\title{
Memristive Non-Volatile Memory Based on Graphene Materials
}

\author{
Zongjie Shen ${ }^{1,2}$, Chun Zhao ${ }^{1,2}, * \mathbb{0}$, Yanfei Qi ${ }^{1,3}$, Ivona Z. Mitrovic ${ }^{2}$, Li Yang ${ }^{4,5}$, \\ Jiacheng Wen ${ }^{1,2}$, Yanbo Huang ${ }^{1,2}$, Puzhuo Li ${ }^{1,2}$ and Cezhou Zhao ${ }^{1,2}$ (D) \\ 1 Department of Electrical and Electronic Engineering, Xi'an Jiaotong-Liverpool University, \\ Suzhou 215123, China; Zongjie.Shen@xjtlu.edu.cn (Z.S.); Yanfei.Qi01@xjtlu.edu.cn (Y.Q.); \\ Jiacheng.Wen16@student.xjtlu.edu.cn (J.W.); Yanbo.Huang16@student.xjtlu.edu.cn (Y.H.); \\ Puzhuo.Li19@student.xjtlu.edu.cn (P.L.); Cezhou.Zhao@xjtlu.edu.cn (C.Z.) \\ 2 Department of Electrical Engineering and Electronics, University of Liverpool, Liverpool L69 3BX, UK; \\ Ivona@liverpool.ac.uk \\ 3 School of Electronic and Information Engineering, Xi'an Jiaotong University, Xi'an 710061, China \\ 4 Department of Chemistry, Xi'an Jiaotong-Liverpool University, Suzhou 215123, China; Li.Yang@xjtlu.edu.cn \\ 5 Department of Chemistry, University of Liverpool, Liverpool L69 3BX, UK \\ * Correspondence: chun.zhao@xjtlu.edu.cn; Tel.: +86-(0)512-8816-1402
}

Received: 30 January 2020; Accepted: 21 March 2020; Published: 25 March 2020

check for updates

\begin{abstract}
Resistive random access memory (RRAM), which is considered as one of the most promising next-generation non-volatile memory (NVM) devices and a representative of memristor technologies, demonstrated great potential in acting as an artificial synapse in the industry of neuromorphic systems and artificial intelligence (AI), due its advantages such as fast operation speed, low power consumption, and high device density. Graphene and related materials (GRMs), especially graphene oxide (GO), acting as active materials for RRAM devices, are considered as a promising alternative to other materials including metal oxides and perovskite materials. Herein, an overview of GRM-based RRAM devices is provided, with discussion about the properties of GRMs, main operation mechanisms for resistive switching (RS) behavior, figure of merit (FoM) summary, and prospect extension of GRM-based RRAM devices. With excellent physical and chemical advantages like intrinsic Young's modulus (1.0 TPa), good tensile strength (130 GPa), excellent carrier mobility $\left(2.0 \times 10^{5} \mathrm{~cm}^{2} \cdot \mathrm{V}^{-1} \cdot \mathrm{s}^{-1}\right)$, and high thermal $\left(5000 \mathrm{Wm}^{-1} \cdot \mathrm{K}^{-1}\right)$ and superior electrical conductivity $\left(1.0 \times 10^{6} \mathrm{~S} \cdot \mathrm{m}^{-1}\right)$, GRMs can act as electrodes and resistive switching media in RRAM devices. In addition, the GRM-based interface between electrode and dielectric can have an effect on atomic diffusion limitation in dielectric and surface effect suppression. Immense amounts of concrete research indicate that GRMs might play a significant role in promoting the large-scale commercialization possibility of RRAM devices.
\end{abstract}

Keywords: non-volatile; memristor; graphene-based materials; operation mechanisms

\section{Introduction}

With the popularization of information technologies, digital problems with increasing amounts of data are receiving considerable attention in the industry. Until 2020, the digital world is expected to be over 40 zettabytes (i.e., 44 trillion gigabytes) with continuous expansion [1]. The rapid growth of computer processors, consumer electronic devices, and information exchange capacity calls for exponentially increased global data storage capability, which presents a high demand for advanced digital memory devices [1,2]. To deal with a huge amount of data, traditional memory devices based on von Neumann architecture are considered to be inadequate in the coming artificial intelligence (AI) era $[3,4]$. Conventional flash memory devices are facing a series of challenges including slow read 
and write $(R \& W)$ speed, limited device density, and high operational voltage [4-7]. As one of the most promising next-generation memory devices and one of the symbols of modern semiconductor technology, emerging non-volatile memory (NVM) devices are offering enhanced performance in terms of simpler structure, lower power energy consumption, reduced data access time, possibility of multiple states, and three-dimensional (3D) integration feasibility [6-11]. The technology report from Luigi Colombo presented the significance of emerging/prototypical NVM technologies [1], as illustrated in Figure 1, including phase-change memory (PCM), magnetic random access memory (MRAM), and resistive random access memory (RRAM). For now, some new NVM products were proposed by several companies such as carbon-nanotube RAM (NRAM) [12,13] and spin-transfer torque (STT)-RAM [14,15]. In the field of future high-performance computers and mobile electronic devices, these emerging NVM devices can work with operation speeds comparable to dynamic random access memory (DRAM) and are expected to replace static random access memory (SRAM) [12-14], which would provide far-reaching motivation to the development process toward so-called universal memory [12-15]. This denotes a single information-storage technology that can combine the best properties of data storage with hardware of memories, eliminating the need for multiple memory hierarchies within the same computing system.

Currently, with the rapid development of solid-state devices and their excellent combination with emerging NVM technologies, impressive achievements of emerging NVM devices such as FeRAM, PCM, MRAM, RRAM, and STT-RAM were made due to the continuous improvement of fabrication processes, as well as through the performance of enhanced devices stimulated by the application of new materials at the nanoscale [6-15]. The relationship between the performance of NVM devices and a variety of materials is under investigation, which is used to improve the figures of merit (FOMs) of NVM devices. A series of nanoscale materials attracted tremendous attention for their different characteristics, including binary transition metal oxides $\left(\mathrm{AlO}_{x}, \mathrm{TiO}_{x}, \mathrm{TaO}_{x}\right.$, and $\left.\mathrm{NiO}_{x}\right)$ [16-19], perovskite materials [20], chalcogenides $\left(\mathrm{MoS}_{2}\right.$ and $\left.\mathrm{WS}_{2}\right)$ [21,22], organic materials [23,24], and graphene-based materials (graphene and graphene oxides) [25-27]. In addition to their atomic-scale thickness, some unique chemical and physical properties exist, such as the flexibility and transparency of these materials, which are highly desirable for the development of information-storage devices to be integrated in wearable systems and smart devices [28,29]. In the last few years, a growing attention was directed to carbon-based memristive devices, especially those based on graphene and graphene oxide (GO), due to the unique properties of this class of materials.

The aim of this work is to provide a comprehensive overview of the state of the most significant advancements of graphene-based memristive devices. A brief introduction of the basic properties and synthesis methodologies of graphene-based materials (mainly graphene and GO) is presented in Section 2. In Section 3, an overview of graphene-based NVM devices (mainly memristors) is given with electrical performance, indicating essential characteristics that should define a working device. In Section 4, the main switching mechanisms based on oxygen ion diffusion and metal ion diffusion are demonstrated. In Section 5, a discussion of graphene-based memristors applied in flexible electronic devices is presented. 


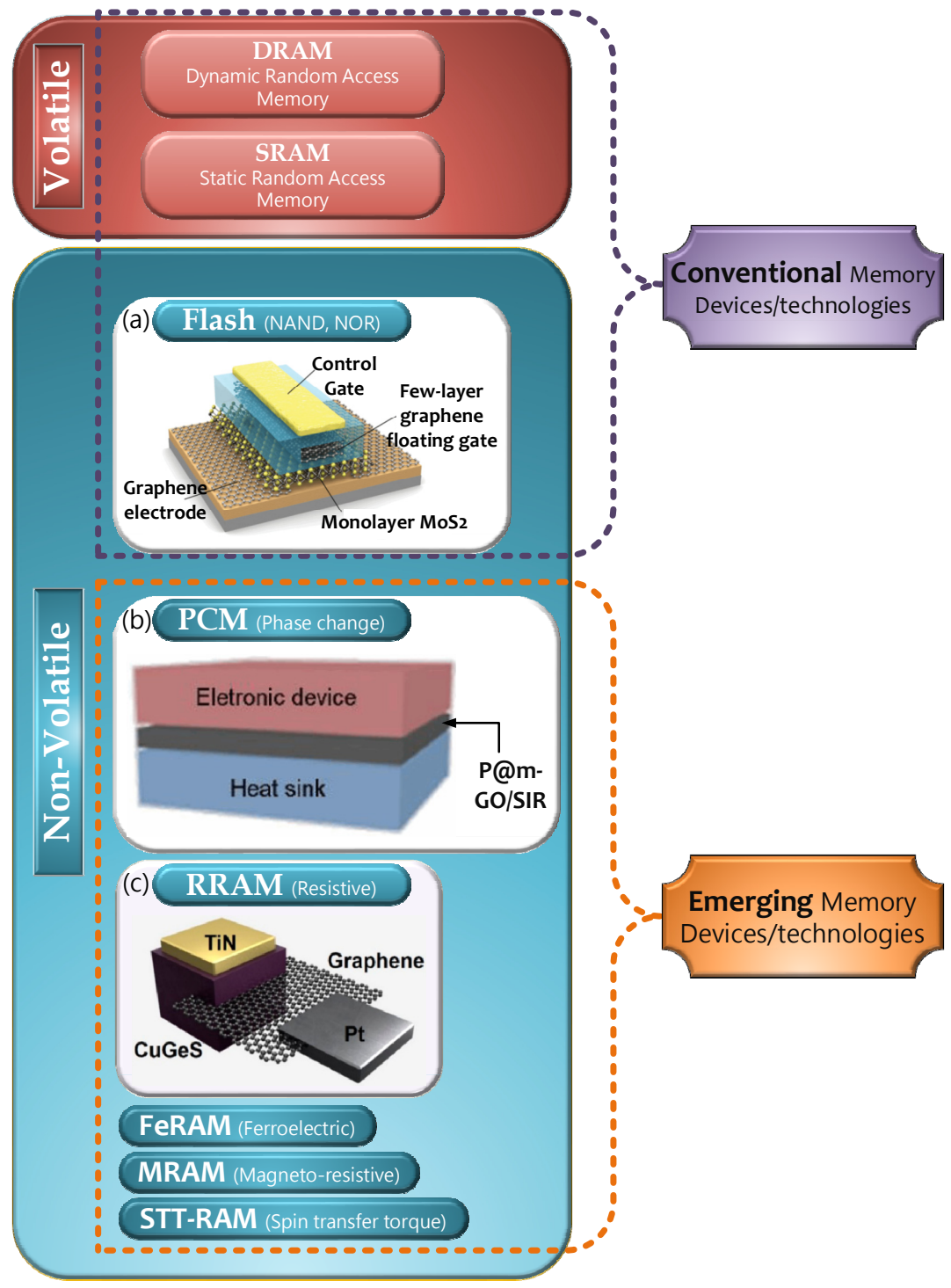

Figure 1. Diagram of conventional and emerging memory devices/technologies, including (a) a schematic illustration of flash memory device fabricated with graphene/ $\mathrm{MoS}_{2}$ materials [2], (b) a schematic representation showing memory device with phase change materials P@m-GO/SIR [30], and (c) a schematic of graphene-based resistive random access memory (RRAM) device [31].

\section{Graphene-Based Materials: Properties and Production}

\subsection{Properties of Graphene-Based Materials}

During the fabrication and operation processes of electronic devices, the inherent properties of available materials receive paramount attention [19,32]. As one of the fundamental composition blocks of graphitic materials in all dimensionalities, graphene is a representative flat monolayer of carbon atoms tightly packed into a two-dimensional (2D) honeycomb lattice [33]. As reported by Geim et al., wrapped-type zero-dimensional (0D) fullerenes, rolled-type one-dimensional (1D) nanotubes, and stacked-type 3D graphite are external variations of graphene. Since the research started about 60 years ago, graphene was used extensively to explain the properties of various carbon-based materials [33]. Graphene is receiving considerable attention due to its special phenomena of predictability and measurability, mainly originating from the massless relativistic particle behavior of electrons [33]. The characteristics of graphene materials including intrinsic Young's modulus (1.0 $\mathrm{TPa})$ and tensile strength (130 GPa) [34,35], excellent carrier mobility at room temperature under 
ambient air conditions $\left(2.0 \times 10^{5} \mathrm{~cm}^{2} \cdot \mathrm{V}^{-1} \cdot \mathrm{s}^{-1}\right)$ [36], and high thermal $\left(5000 \mathrm{Wm}^{-1} \cdot \mathrm{K}^{-1}\right)$ and electrical conductivity $\left(1.0 \times 10^{6} \mathrm{~S} \cdot \mathrm{m}^{-1}\right)[15,37]$ make this material applicable as an active material in a variety of interdisciplinary fields such as supercapacitors [38,39], sensors [40,41], energy storage devices [42,43], and multifunctional fillers in nanocomposite materials [44].

Apart from the properties of graphene and cost consideration, memory devices developed with high-quality materials, a sophisticated nano-fabrication process, and sufficient prediction may demonstrate enhanced performance. However, in practice, a tradeoff among device performance, nano-scale fabrication process, and suitable cost is necessary, which indicates that it is essential to investigate novel memories that are adaptable to modern electronics. As the most representative category among 2D materials, graphene and related materials (GRMs) are expected to promising materials for the development of modern NVM devices due to their intriguing physical and chemical properties. For instance, the high mobility of graphene may contribute to faster operation speeds and lower operation times for NVM devices; the atomically thick structure of graphene can be helpful to realize the compact integration density of single devices; the solution-processable compatibility of graphene improves the successful probability of flexible memory devices with lower cost and a simpler fabrication method. Based on these considerations, GRM application for NVM devices with properties of higher density, faster operation speed, and lower energy consumption is receiving increasing interest. Hong et al. demonstrated a silicon (Si)-based flash memory device with graphene as a floating gate, which presented a wide operation window and low cell-to-cell interference with low operation voltage [45]. Qi and Shen et al. reported an RRAM device with a solution-processed GO thin film, which operated with an operation voltage lower than $2 \mathrm{~V}$ and a $\sim 10^{3}$ on/off ratio [19]. These results suggest the great potential of GRMs in the NVM industry.

\subsection{Synthesis Technologies of Graphene-Based Materials}

It is over 10 years since Geim and Novoselov firstly found a way to fabricate graphite thin flakes, and several processes for the synthesis of graphene-based materials are mainly investigated using thin films. In general, it is easy to complete the deposition of a graphene monolayer onto a metal substrate, and the progress of this approach demonstrates the great potential of large-area single crystals [25,46-48]. Growth techniques reported in the literature can be observed in Table 1, including chemical vapor deposition (CVD), atomic layer deposition (ALD), nucleation and growth, liquid-phase exfoliation (LPE), electrochemical exfoliation, and a solution process [6,49-58]. Apart from graphene-based materials, some researchers like Zhang et al. also focused on other 2D materials such as $\mathrm{MoS}_{2}$-based composites, which presented excellent performance in the application of memristive devices, similar to that using graphene-based materials [58].

Table 1. Comparison among main synthesis technologies and applications for graphene and its derivatives [6,49-58].

\begin{tabular}{lllllll}
\hline $\begin{array}{l}\text { Synthesis } \\
\text { Methods }\end{array}$ & $\begin{array}{l}\text { Chemical Vapor } \\
\text { Deposition }\end{array}$ & $\begin{array}{l}\text { Atomic Layer } \\
\text { Deposition }\end{array}$ & $\begin{array}{l}\text { Nucleation and } \\
\text { Growth }\end{array}$ & $\begin{array}{l}\text { Liquid Phase } \\
\text { Exfoliation }\end{array}$ & $\begin{array}{l}\text { Electrochemical } \\
\text { Exfoliation }\end{array}$ & $\begin{array}{l}\text { Solution } \\
\text { Deposition }\end{array}$ \\
\hline \multirow{3}{*}{ Materials } & Graphene & Graphene & Graphene & GO & GO & GO \\
& h-BN & h-BN & TMD & TMD & TMD & FeRAM \\
& TMD & TMD & FeRAM & MRAM & FeRAM & FeRAM \\
& FeRAM & MRAM & PCM & RRAM & RRAM & Flash \\
Devices & MRAM & RRAM & RRAM & Flash & & \\
& TRAM & SRAM & & & & \\
\hline
\end{tabular}

As typical conventional deposition methods, CVD and ALD are not only used to grow graphene, as well as multicomponent heterostructures of II-VI, III-V, and oxide materials, but they are also applied to the production of large-scale hexagonal boron nitride (h-BN) and two-dimensional transition metal dichalcogenides (2D-TMD) [59,60]. Currently, high-quality graphene materials with monocrystalline and polycrystalline structures are only reported to be grown by CVD and thermal desorption of Si 
from $\mathrm{SiC}$ single crystals [61], and notable progress was achieved in the deposition of graphene on metals $[30,62,63]$. In addition, although the growth of h-BN and TMD materials is also investigated, the growth of large-area monolayers or few-layer single crystals of h-BN and TMDs is still a major challenge $[64,65]$. Apart from CVD and ALD, the nucleation and growth approach was also investigated, showing that graphene single crystals could be deposited on metals like copper $(\mathrm{Cu})$ and lithium (Li) $[53,66]$. During the nucleation and growth process, edge functionalization for graphene growth on noncatalytic surfaces may be required due to a higher edge growth rate being observed in $2 \mathrm{D}$, which can be observed in TMD materials [60]. The LPE method is a versatile technology which was used to exploit 2D materials such as graphene, TMD, and h-BN from substrates [67-69]; these materials can then be applied into the large-scale production of 2D material-based devices. LPE can also be used to fabricate 2D material inks in different solvents [70-72], which reveals its great potential in flexible device fabrication. The electrochemical exfoliation method reported by Feng, Müllen, and co-workers [1] demonstrated that electrochemically exfoliated graphite provides graphene flakes from one to three layers with a high yield of $>80 \%$, a high $\mathrm{C} / \mathrm{O}$ ratio of $\sim 12$, a sheet resistance value of $4.8 \mathrm{k} \Omega \cdot \mathrm{m}^{-1}$, and hole mobility of $233 \mathrm{~cm}^{2} \cdot \mathrm{V}^{-1} \cdot \mathrm{s}^{-1}$ for a single sheet [1]. Currently, solution process methods of graphene and GO materials also receive considerable attention, mainly including spin coating, dip coating, and drop casting [73-78]. A comparison of these approaches is shown in Table 2.

Table 2. Comparison among main solution-processed technologies [73-78].

\begin{tabular}{llll}
\hline Item & Spin Coating & Dip Coating & Drop Casting \\
\hline Fabrication cost & Low & High & Low \\
Fabrication equipment & Spin coater, hot plates & Dip coater, hot plates & Hot plates \\
Fabrication time & $<1 \mathrm{~h}$ & $>2 \mathrm{~h}$ & $<1 \mathrm{~h}$ \\
Dielectric thickness & Thin and uniform & Thick and uniform & Thick and heterogeneous \\
Device performance & Long retention & Short retention & Short retention \\
& time/endurance cycles & time/endurance cycles & time/endurance cycles \\
\hline
\end{tabular}

\section{Memory Devices and Memristors Based on Graphene-Based Materials}

\subsection{FoM (Figure of Merit) of Memory Devices}

In order to produce memory devices with smaller cell size, faster operation speed, lower power consumption, and lower fabrication cost, an FoM assessment of memory devices is always the priority $[79,80]$. Apart from the performance measurement of devices under development, FoM comparisons with other state-of-the-art market products are also considered. In general, the FoM assessment of NVM devices commonly focuses on basic characteristics in terms of operation speed, reliability, power consumption, scalability, and cost (Table 3) [15,79-89].

Table 3. Figure of merit (FoM) comparison among main conventional and emerging memory devices [15,79-89].

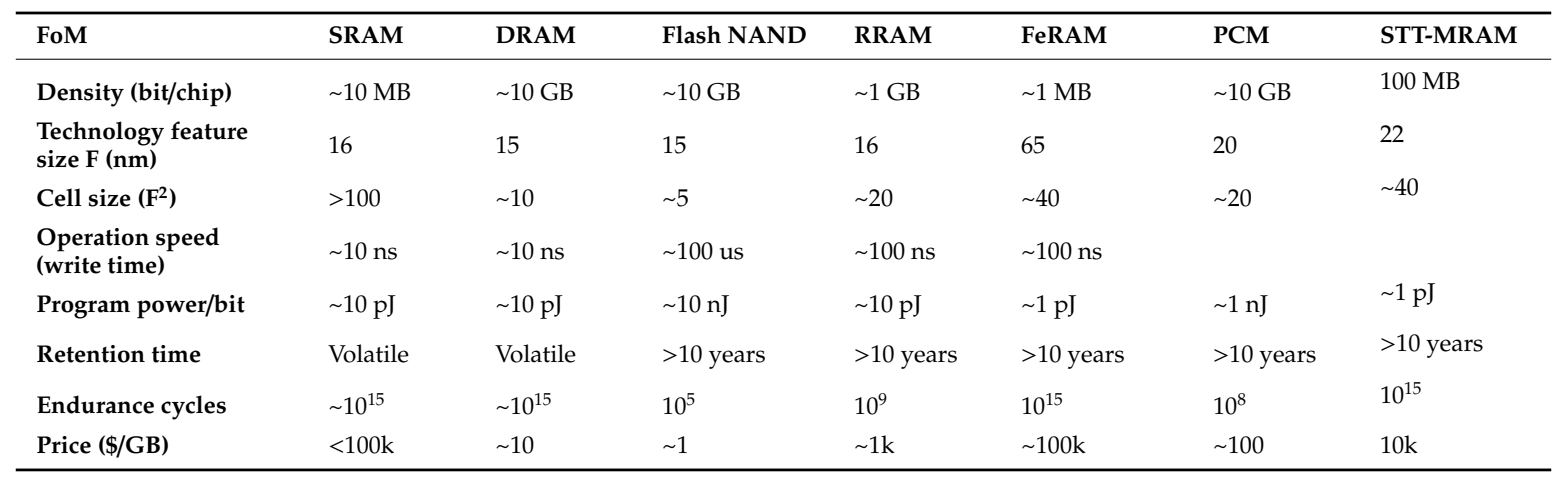




\subsubsection{Operation Speed}

The random-access time of a single-memory cell and the effective time of write/erase operation performance (latency) are used to determine the operation speed of memory devices. For now, high-performance volatile memory devices, such as SRAM and DRAM, are commonly used in processors, which perform short latencies $(<100 \mathrm{~ns})$, but are more expensive and occupy larger chip areas as compared to silicon flash memories [81,82]. Although some disadvantages including higher cost and lower density exist, emerging NVM technologies demonstrated an operation time comparable to current SRAM and DRAM $[83,84]$.

\subsubsection{Reliability}

Write endurance and data retention properties are considered as main characteristics of NVM device reliability. Write endurance is the quantized behavior of the anti-fatigue-degradation characteristic of a single NVM device, which is determined as the highest number of write/erase cycles that can be operated before the NVM cell fails to be reliable. The endurance also demonstrates the number of sustained cycles of the device before reaching the breakdown state $[15,85]$. Data retention refers to the amount of time for which the information can be sustained within the NVM cell, which demonstrates the sustained time during which the device can keep the internal resistance states without external power $[86,87]$. A higher number of endurance cycles and a longer retention time are essential to maintain reliability in the device's lifetime, which can avoid device failure and maintain device readability.

\subsubsection{Power Consumption}

Device power consumption is made up of static power dissipation and dynamic power consumption. Static power dissipation mainly results from the aging process of storage hardware, and the main source of dynamic power consumption is memory data transition [90-93]. Compared with conventional silicon-based memory, memory devices with emerging memory technologies, including RRAM, PCM, FeRAM, and STT-MRAM, demonstrate less power consumption. In addition, these emerging memory devices show stronger resistance against the research trend of device miniaturization [94,95], which is applied to help data centers deal with their ever-increasing power requirement.

\subsubsection{Scalability}

In order to achieve a memory device with excellent performance, the scalability of the memory cell is receiving more and more attention due to the increasing density of memory devices, which indicates that the memory cell must be scaled. Apart from processing problems introduced by device scaling, another limitation factor, i.e., cross-talk between neighboring cells, cannot be neglected $[20,96]$. Typical values of bit density for state-of-the-art market products are expressed as the number of GB per chip together with the corresponding cell size expressed as multiples of $F^{2}$ ( $F$ is the technology feature size). For now, the novel program of a semiconductor product with over 64 stacking layers of memory was realized on one microchip, which presents a high bit density of $0.5 \mathrm{~GB} / \mathrm{mm}^{2}[97,98]$, which was considered as an achievement with record-high bit density.

\subsubsection{Cost}

In order to determine the commercial feasibility of a product program, during the manufacture of one memory chip with NVM technology, the cost of related materials, the fabrication process, and the integrated system should receive enough consideration. With the development of future semiconductors in the industry, the acceptable cost of a memory device will depend on target applications in terms of embedded hardware design, low-power-consumption environment, high speed, and high capacitor demand $[99,100]$. 


\subsection{Memristor}

As one of the most promising non-volatile memory devices, the memristor demonstrates great potential in terms of enhanced reliability, fast operation speed, lower power consumption, and lower market cost, which can be observed in Table 3. In 1971, the theoretical concept of the memristor was proposed by Chua, which eluded the attention of integrated circuit designers as a single-device electronic implementation for the past three decades. With Chua's perspective, all 2D NVM devices based on resistance switching performance are memristors, regardless of the device materials and physical operating mechanisms [101-104]. Researchers from Hewlett-Packard (HP) Laboratory firstly reported that they developed high-density non-volatile memories with a crossbar-based structure [105]. With a combination of complementary metal-oxide-semiconductor (COMS) technology and nanoscale-level processed memristors, profound influence will be observed on not only the flash memory industry but also the computing process of digital and neuromorphic systems. The memristor device exhibits a dynamical resistance state determined by its excitation history, which is used to build transistor-less nonvolatile semiconductor memory (NVSM), commonly known as RRAM [101-106].

Chua proposed the existence of another two-terminal component in the circuit, in addition to the resistor, capacitor, and inductor, which operated on the basis of a relationship among voltage $(v)$, current $(i)$, magnetic flux $(\varphi)$, and charge $(q)$ [107]. The resistor is used to describe the relationship between $v$ and $i$, the capacitor is the connection between $v$ and $q$, and the inductor links $\varphi$ and $i$. Therefore, in general, the memristor can be used to define the connection between $\varphi$ and $q$. To be more precise, the definition of a memristor is related to not only the flux as a magnetic magnitude but also the mathematical magnitude corresponding to the time-integral of the voltage across the device $[101,102,104,106]$. The most obvious characteristic of a memristor is that its resistance changes with the amount of current passing through the device. The resistance will stay at the previous state even if the passing current stops. Until the device receives reverse current, the resistance state will change.

With the development of memristor research for about half a century, RRAM devices received considerable attention as the most typical memristor. Apart from research on device performance, recent research was directed toward the study of materials with resistive switching (RS) function, such as binary transition metal oxides $\left(\mathrm{TiO}_{\mathrm{x}}, \mathrm{AlO}_{\mathrm{x}}\right.$, and $\left.\mathrm{NiO}_{\mathrm{x}}\right)$ [3,107-111], perovskite compounds $\left(\mathrm{CH}_{3} \mathrm{NH}_{3} \mathrm{PbI}_{3}\right.$ and $\left.\mathrm{CsPbBr}_{3}\right)$ [54,55,112], ferromagnetic materials [112,113], biological materials [114,115], and graphene-based materials (graphene and GO) [30,116].

\subsubsection{RRAM Device Characteristics}

RRAM devices fabricated with a typical MIM (metal-insulator-metal) sandwich structure are electrically characterized with two different resistance states, which are generally referred to as the high-resistance state (HRS) and low-resistance state (LRS). The high-resistance value of the device shows the low-conductance state, while the device demonstrates the high-conductance state with the low-resistance value. The on/off ratio is determined by the ratio between HRS and LRS. With the applied voltage bias, the set operation is defined from HRS to LRS, and the reset operation is the transition from LRS to HRS. Stop voltages of the set and reset process are defined as $V_{\text {SET }}$ and $V_{\text {RESET }}$. In general, two different switching types are defined as unipolar and bipolar [3,107-111], as illustrated in Figure 2. The unipolar switching mode is defined by the amplitude of the applied voltage bias, while the bipolar switching depends on the polarity of the applied voltage bias. In addition, as an NVM device, the endurance and retention properties of RRAM are also the basis of device reliability. 
(a)

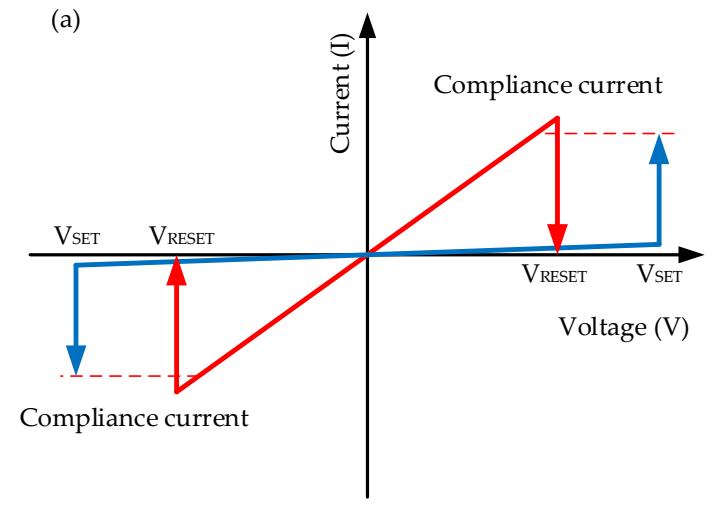

(b)

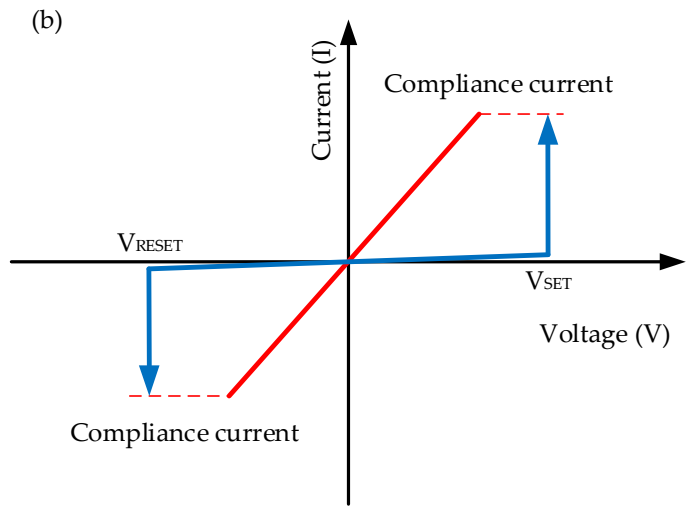

Figure 2. Unipolar (a) and bipolar (b) resistive switching (RS) behavior of RRAM device [3,107-111].

\subsubsection{RRAM Based on Graphene and Its Derivatives}

In general, graphene and its derivatives are investigated as resistive switching (RS) and electrode materials in RRAM devices. Exfoliated graphene sheets with RS performance in a field-effect transistor (FET) were reported by Tsang and Delgado-Notario et al. [117-119]. The external electrical field of the gate electrode with the presence of $\mathrm{OH}^{-}$and $\mathrm{H}+$ absorbed on the $\mathrm{SiO}_{2} / \mathrm{Si}$ substrate induced a chemical modification in the crystal structure of graphene. Bruck et al. reported a graphene-dielectric-layer-based RRAM device with an on/off ratio of $~ 100$ and switching time of 100 us in 2008, as illustrated in Figure 3 [119]. After that, an RRAM cell fabricated with graphitic stripe layers was reported by Li et al., which demonstrated a higher ratio $\left(\sim 10^{7}\right)$ and faster switching speed $(\sim 1 \mathrm{us})$ [1]. For now, as one of the most representative graphene derivatives, GO receives more consideration due to its similar flexibility and robustness to graphene via a simple synthesis method and its enhanced RS performance as a dielectric medium [120]. GO can be fabricated via the oxidation and exfoliation of graphite before being dispersed in water; the GO suspension can be easily deposited on the bottom electrode (BE) via various methods including spin coating, drop coating, and vacuum filtration [121-123]. Following a thermal annealing process, the GO thin film can be fabricated after a suspension deposition process. In general, the annealing temperature is commonly lower than $200{ }^{\circ} \mathrm{C}$, and the thickness range of obtained GO thin films is from about a few tens of nanometers $(\mathrm{nm})$ to a few tens of micrometers $(\mu \mathrm{m})[19,121,124-128]$.

(a)

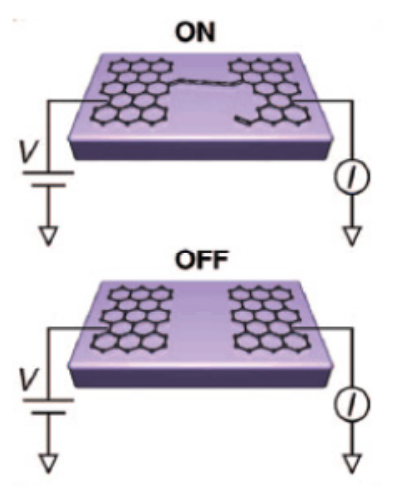

(b)

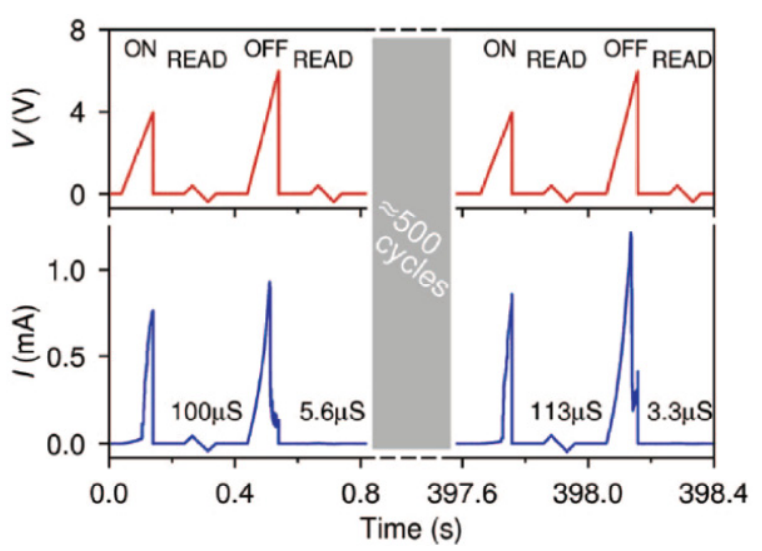

Figure 3. (a) Proposed schematic atomic configurations in the on and off states of transistor-type memory. (b) Repeatable programming over hundreds of cycles [119].

In addition, various groups investigated graphene-based composite materials, such as combinations of $\mathrm{GO} / \mathrm{rGO}$ (reduced GO) with polymers, small molecules, and metal nanoparticles (NPs). 
An Al/TPAPAM-GO/ITO device was proposed by Zhuang et al. [129]. An arylamine-containing conjugated polymer TPAPAM was chosen as a hole-transport agent due to its excellent hole injection, high mobility, and low ionization potential. TPAPAM-GO was fabricated using soluble triphenylamine-based polyazomethine (TPAPAM), which was used to covalently graft GO and form TPAPAM-GO. TPAPAM-GO-based RRAM devices demonstrated typical bipolar RS performance with an on/off ratio of $\sim 10^{3}$ at $\sim 1 \mathrm{~V}$ operation voltage and rewritable memory performance with stable resistance states for more than $10^{8} \mathrm{~s}$ [129]. Jin et al. [130] reported a device with a ferrocenylphenyl-NHCO-GO (FPArGO) RS layer synthesized from ferrocene and GO. Ferrocene is a small molecule with $18 \pi$-electrons and a redox-active organometallic compound at low potential. They synthesized FPArGO as a conjugated graphene-based material with redox active small molecules covalently bonded to an active layer of rGO. Enhanced RS performance of Al/FPArGO/ITO RRAM devices can be observed with an operation voltage lower than $\sim 2 \mathrm{~V}$ and an on/off ratio around $\sim 10^{3}$. The write and read cycles could be repeatedly performed in excess of 1000 cycles, and the data sustainment time was beyond $10^{4} \mathrm{~s}$ [130]. Cui et al. [130] proposed nonvolatile memory devices with Au nanoparticles (AuNPs) and reduced GO (rGO) sheets in both horizontal and vertical structures. Additionally, 4-mercapto-benzenediazonium tetrafluoroborate (MBDT) salt was used as a $\pi$-conjugated bifunctional molecular bridge to chemically bind AuNPs to the rGO channel, which created functionalized rGO (frGO). Al/AuNPS-frGO/ITO memory devices exhibited bipolar IV characteristics with an operation voltage lower than $\sim 3 \mathrm{~V}$, an on/off ration higher than $\sim 10^{3}$, and retention time sustained over $700 \mathrm{~s}$ [130]. In general, compared with memory devices with pure GO materials, a GO layer combined with other compound materials can exhibit enhanced RS performance.

For RRAM devices with a GO-based MIM structure, the choice of top electrode (TE) and bottom electrode (BE) materials always receives the most attention. Table 4 exhibits various TE and BE combinations of GO-based RRAM devices. It is suggested that the RS performance of GO-based RRAM devices is mainly related to the different work functions $\left(\phi_{M}\right)$ of TE and BE $[120,121,131]$. In Table 4, $\mathrm{Au}, \mathrm{Al}, \mathrm{Ag}, \mathrm{Cu}$, and Ti are always used as the TE while $\mathrm{Pt}$ is commonly used as the BE in electronic devices. The $\phi_{\mathrm{M}}$ of $\mathrm{Pt}$ is $\sim 5.65 \mathrm{eV}$, while the $\phi_{\mathrm{M}}$ of $\mathrm{Au}, \mathrm{Ti}, \mathrm{Ag}$, and $\mathrm{Cu}$ is $\sim 5.1 \mathrm{eV}, \sim 4.33 \mathrm{eV}, \sim 4.26 \mathrm{eV}$, and $\sim 4.65 \mathrm{eV}$, respectively. The existence of a work function difference $\left(\Delta \phi_{\mathrm{M}}\right)$ between TE and BE, namely, an asymmetric work function between active and inert electrode, results in the appearance of RS performance in these GO-based RRAM devices [120-124,131,132]. For GO-based devices with ITO (indium tin oxide) as the BE, the $\phi_{\mathrm{M}}$ of ITO is $\sim 4.9 \mathrm{eV}$, which is very close to the $\phi_{\mathrm{M}}$ of metal Au. Therefore, no effective RS performance can be observed in Au/GO/ITO structure devices [124,133]. It is worth noting that devices with $\mathrm{Al}(\sim 4.28 \mathrm{eV})$ as the TE show unusual performance, in contrast to devices with other TE metals. Although the $\Delta \phi_{\mathrm{M}}$ between $\mathrm{Al}$ and $\mathrm{Pt}$ is higher than $1.0 \mathrm{eV}$, successful RS behavior cannot be observed in Al/GO/Pt RRAM devices. However, as illustrated in Figure 4, $\mathrm{Al} / \mathrm{GO} / \mathrm{Al}$ RRAM devices with no $\Delta \phi_{\mathrm{M}}$ exhibit enhanced RS performance. Compared with metals like $\mathrm{Au}, \mathrm{Ag}$, and $\mathrm{Cu}$, local oxidation is more likely to occur on $\mathrm{Al}$ electrodes at the interface, which might be a decisive influence factor explaining its unique performance [120-124,131-133]. As reported by Liu et al. [8], the work function difference between TE and BE metals has significant effects on device characteristics and performance. RRAM devices made from TE and BE metals with larger work function difference have a higher and more stable on/off resistance ratio with larger set and reset voltages.

Table 4. Comparison among GO-based RRAM devices with various electrodes [121,124,132,133].

\begin{tabular}{|c|c|c|c|c|c|c|c|c|c|}
\hline TE & $\mathrm{BE}$ & RS Behavior & On/Off Ratio & $\mathrm{V}_{\text {Forming }}(\mathrm{V})$ & $\mathrm{V}_{\text {SET }}(\mathrm{V})$ & $\mathrm{V}_{\text {RESET }}(\mathrm{V})$ & Endurance (Cycle) & Retention (s) & Reference \\
\hline $\mathrm{Au}$ & $\mathrm{Pt}$ & Bipolar & $\sim 60$ & $\sim 2.8$ & $\sim 0.7$ & $\sim \sim 0.6$ & $>100$ & $>10^{5}$ & [132] \\
\hline $\mathrm{Ag}$ & $\mathrm{Pt}$ & Bipolar & $\sim 60$ & $\sim 0.5$ & $\sim 0.5$ & $\sim-0.3$ & $>100$ & $>10^{5}$ & [132] \\
\hline $\mathrm{Cu}$ & $\mathrm{Pt}$ & Bipolar & $\sim 15$ & $\sim 1.8$ & $\sim 0.5$ & $\sim-0.6$ & $>100$ & $>10^{4}$ & [132] \\
\hline $\mathrm{Au}$ & ITO & N.A. & N.A. & N.A. & N.A. & N.A. & N.A. & N.A. & {$[121,133]$} \\
\hline $\mathrm{Al}$ & $\mathrm{Al}$ & Bipolar & $\sim 10^{3}$ & N.A. & $\sim 2.0$ & $\sim-2.5$ & $>100$ & $>10^{5}$ & [124] \\
\hline $\mathrm{Al}$ & ITO & Bipolar & $\sim 10^{3}$ & N.A. & $\sim 2.0$ & $\sim-1.5$ & $>100$ & $>10^{9}$ & {$[133]$} \\
\hline $\mathrm{Al}$ & $\mathrm{Pt}$ & N.A. & N.A. & N.A. & N.A. & N.A. & N.A. & N.A. & [132] \\
\hline
\end{tabular}


(a)

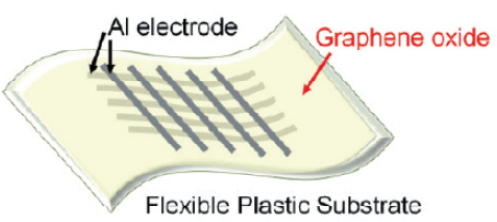

(c)

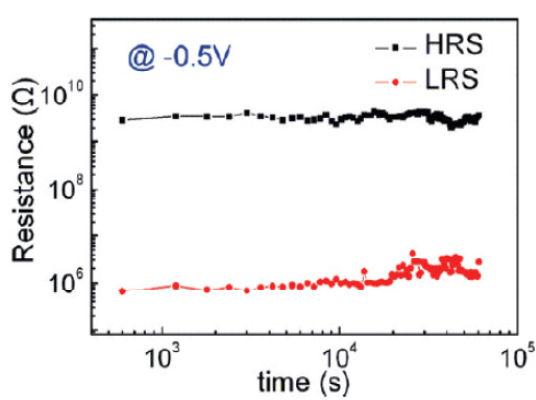

(b)
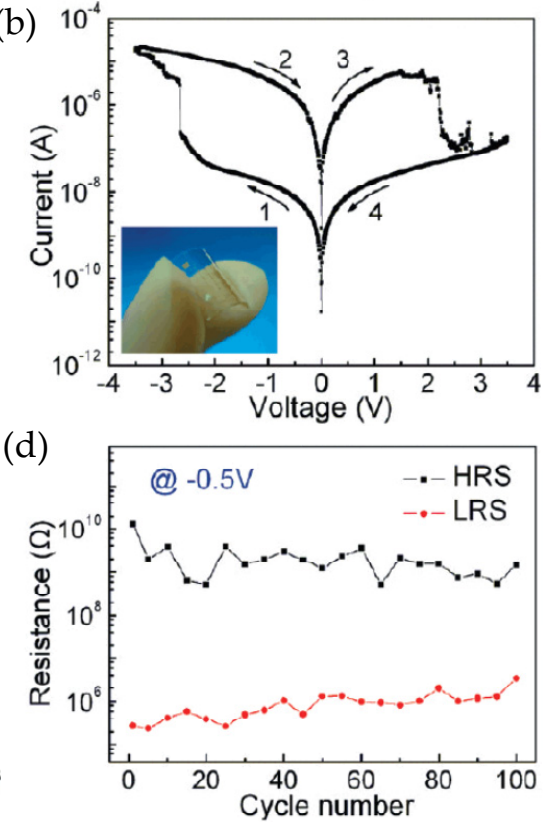

Figure 4. (a) Schematic illustration of $\mathrm{Al} / \mathrm{GO} / \mathrm{Al} / \mathrm{PES}$ flexible crossbar memory device; (b) Typical I-V characteristic of $\mathrm{Al} / \mathrm{GO} / \mathrm{Al} / \mathrm{PES} \mathrm{RRAM}$ device; (c) Retention property of $\mathrm{Al} / \mathrm{GO} / \mathrm{Al} / \mathrm{PES}$ device read at $-0.5 \mathrm{~V}$; (d) Endurance performance of Al/GO/Al/PES device measured during 100 sweep cycles [124].

Apart from the choice of TE and BE, other features like surface roughness and obtained thickness of the GO dielectric layer cannot be neglected, as illustrated in Figure 5 [132,133]. Figure 5a-d demonstrate the surface roughness of a GO thin film deposited on different BEs, observed using an atomic force microscope (AFM). The low surface roughness of GO thin films can be obtained with its deposition on a smooth BE, such as inert metals like Pt (RMS $2.142 \mathrm{~nm}$ ) and compounds like ITO (RMS $3.770 \mathrm{~nm}$ ). Higher roughness is observed for GO thin films with BEs like TaN and Au due to the existence of cracks. Because of the presence of these cracks and a rough surface in GO dielectric layers, penetration might occur more easily in electrode materials, leading to failure of effective RS performance. Device discrepancy likely results from contrasting thermal properties between $\mathrm{GO}$ and electrode materials. As illustrated in Figure 5e, the forming voltages of $\mathrm{Cu} / \mathrm{GO} / \mathrm{Pt}$ RRAM devices are obviously influenced by the thickness of GO films. During the forming process, the required voltages synchronously increase with the thickness of GO thin films, which indicates that the internal electrical field in the GO dielectric layer plays a decisive role in the forming operation. After the forming operation, Figure $5 \mathrm{f}$ demonstrates the resistance states (HRS and LRS) of $\mathrm{Cu} / \mathrm{GO} / \mathrm{Pt}$ RRAM devices. The relationship between resistance values and thickness of GO thin films can be considered as a function, as reported by Zhuge et al. [132]. 

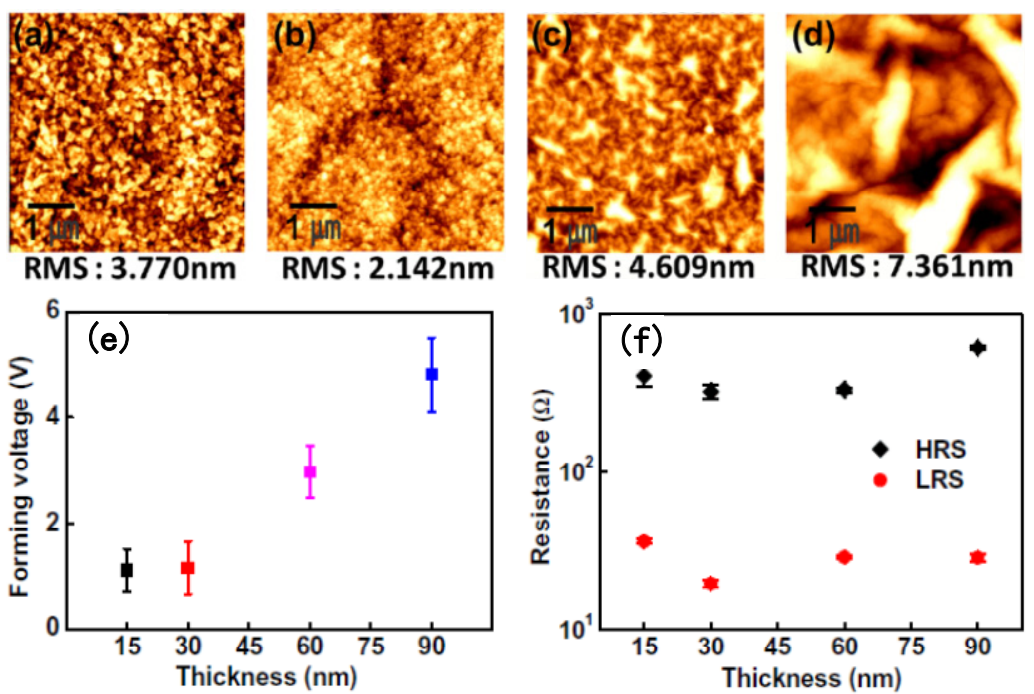

Figure 5. The surface roughness of GO after deposition on various bottom electrodes: (a) ITO, (b) Pt, (c) $\mathrm{Al}$, and (d) Au. (e) GO film thickness dependence of forming voltage of $\mathrm{Cu} / \mathrm{GO} / \mathrm{Pt}$ memory cells. (f) High- and low-resistance states (HRS and LRS) of $\mathrm{Cu} / \mathrm{GO} / \mathrm{Pt}$ memory cells, plotted against the thickness of GO [132,133].

\section{Switching Mechanism of Graphene-Based Memristor}

\subsection{Oxygen Ion-Based Switching Mechanism}

Several studies reported that the main reason for RS performance in dielectric layers based on graphene and its derivatives, especially GO layers, is the diffusion of oxygen ions or vacancies [19,134-139]. In general, the RS behavior and switching mechanism are influenced by the fabrication methods and hybridization state of graphene-based material dielectric layers, the deposition techniques of electrode layers, and the choice of TE and BE materials. Some studies agreed that the structure modification of the entire dielectric layer results in a comprehensive effect on RS behavior $[123,131,140]$. However, other studies considered that the RS behavior is a regional phenomenon, as illustrated in Figure $6 \mathrm{a}$, which is associated with the contact resistance between the TE and dielectric layer [22,38,141-143].

(a)

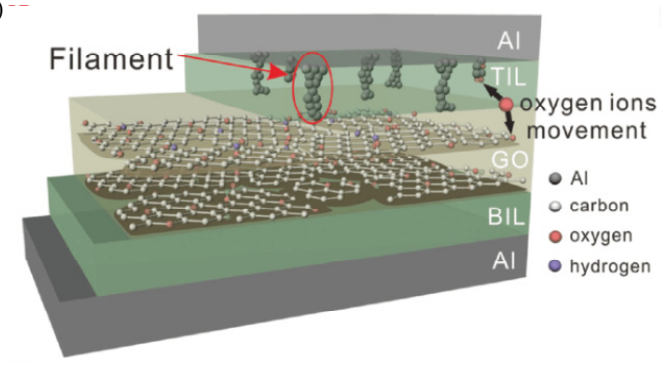

(b) Pristine device (Off state)

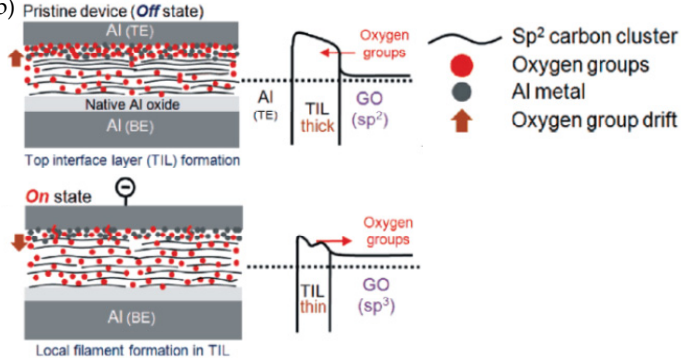

Figure 6. (a) Schematic of oxygen ion movement model of Al/GO/Al RRAM device. (b) Schematic of the proposed bipolar RS model for Al/GO/Al crossbar memory device [124,143].

In 2010, as one of the first examples focused on the oxygen ion-based switching mechanism of graphene-based memory devices, Kim et al. proposed Al/GO/Al crossbar memory on flexible substrate [124]. As illustrated in Figure 6b, due to the redox reaction process occurring at the interface between $\mathrm{GO}$ and the $\mathrm{Al}$ electrode, the resulting interface layer plays a decisive role in the switching process. This $\mathrm{AlO}_{x}$ layer acts as an insulating layer and influences the HRS. With the applied negative voltage bias, electrical-field-induced oxygen ions diffuse into the GO layer, which forms local conductive 
filaments (CFs), resulting in the device switching into the LRS. However, ohmic conduction did not occur at the LRS due to the GO film transforming into an $s p^{3}$-bonded state without CFs [124].

One year later, Panin et al. also reported a device with an $\mathrm{Al} / \mathrm{GO} / \mathrm{Al}$ structure, which presented the importance of local resistance state induced by the contact of Al and GO layers [144]. With the positive voltage bias applied onto the $\mathrm{Al}$ layer in the forming process, a highly resistive region formed near the TE. Under the effect of an external electrical field, oxygen ions stored in the dielectric layer drift to the electrode, which can result in the continuous formation of an $s p^{3}$ hybridization layer between $\mathrm{Al}$ and the structure-modified GO layers at the HRS. When a negative voltage bias is applied onto the TE Al layer, the reverse diffusion of oxygen ions leads to LRS CFs near the contact interface under the effect of a negative electrical field [144].

According to a report from Wang et al. [145], the diffusion of oxygen ions can be used to explain the switching performance, as well as the operation speed, of graphene-based RRAM devices. The oxygen ion migration of a device is affected by the existence of a barrier on hopping energy. The inhomogeneity of electron density in a dielectric layer is a decisive influence factor in the electron extraction and injection process, which significantly affects the performance of the hopping energy barrier. During the set operation, the hopping energy barrier is reduced due to the electron extraction of the dielectric layer, which increases the oxygen ion mobility, as illustrated in Figure 7. Conversely, the electron injection process from the metal electrode into the dielectric layer during the reset operation increases the energy barrier and decreases the diffusivity of oxygen ions. Therefore, compared with its long set speed ( $~ 80$ us), the RRAM device in Reference [145] showed a shorter speed ( $90 \mathrm{~ns})$ in the reset operation.

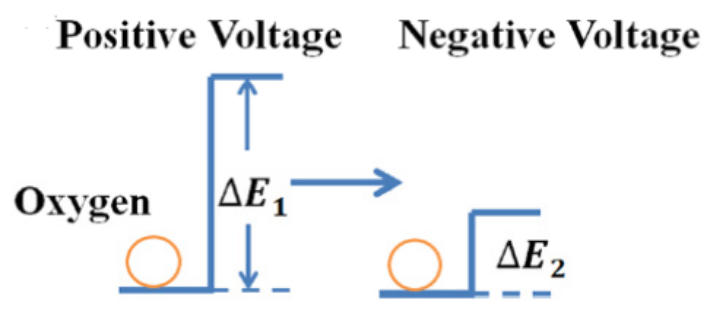

Figure 7. Schematic of oxygen hopping barrier change model for Al/GO/ITO RRAM devices [145].

\subsection{Metal Filament-Based Switching Mechanism}

Apart from the switching mechanism based on oxygen ion diffusion, a metal filament-based mechanism was also used to explain the RS behavior of graphene-based RRAM devices, which mainly depends on electrode materials $[99,132,133,146,147]$. Zhuge et al. reported this mechanism in a metal/GO/Pt structure device, as illustrated in Figure 8 [132]. In this case, several metals such as Ag, $\mathrm{Ti}, \mathrm{Cu}$, and $\mathrm{Au}$ were used as the TE in the devices. They inferred that the low switching voltage was related to the ion diffusion coefficient of electrode materials. Metal/GO/Pt devices with an active TE like $\mathrm{Ag}, \mathrm{Ti}$, and $\mathrm{Cu}$ with a large ion diffusion coefficient were more likely to be operated with low forming voltage. $\mathrm{Au} / \mathrm{GO} / \mathrm{Pt}$ devices which worked with higher forming voltage resulted from gold being very difficult to oxidize to ions [132]. During the set operation, the external electrical field induced by a positive voltage bias on the TE resulted in the metal generating ions in the graphene-based dielectric layer, thereby forming the CF paths, which caused the device to be in the on state that was maintained until the presence of a negative voltage bias. After the TE experienced a negative voltage bias, the metal-based CF paths were dissolved by the electrochemical effect between the metal and dielectric layer, which caused device to be in the off state [132,133].

In addition to the two main switching mechanisms discussed above, a mechanism affected by GO-based bulk was also investigated. It is worth mentioning that Wah et al. presented a compact model of hybridization state modulation for GO-RRAM, which is one of the most effective explanations for the bulk mechanism $[28,139,148-150]$. The proposed model associates the resistance switching mechanism 
with the electrical-driven modification of $s p^{2}$ cluster density in the switching layer. A simulation program with integrated circuit emphasis (SPICE) model incorporating the proposed compact model was developed for parameter calibration. Firstly, they provided the transport mechanism in GO-RRAM based on hybridization state modulation, as illustrated in Figure 9a. The amorphous $s p^{3}$ matrix isolates these graphene-like clusters, which introduces a high tunneling barrier and substantially limits the electron tunneling probability between the $s p^{2}$ clusters. The initial resistance of GO-RRAM is determined by the $s p^{2}$ clusters. The increasing $s p^{2}$ density induced by oxygen functional group reduction results in hopping paths for the electron, which completes the set operation (HRS to LRS) $[149,151]$. Conversely, with a positive voltage bias, oxygen ions drift back to the GO layer, while $s p^{2}$ clusters are hybridized into $s p^{3}$ bonding, which reduces the $s p^{2}$ density and switches the device back into the HRS. Acting like intermediate traps, $s p^{2}$ clusters support continuous electron flow, which can be explored via a multi-phonon trap-assisted tunneling (MTAT) mechanism [151]. Figure 9b exhibited the SPICE macro implementation of the proposed compact model, as well as a comparison of I-V characteristics of the SPICE simulation and experimental result. The I-V characteristic of the proposed compact model has high correlation with the experimental data [148,151]. A similar discussion mechanism of bulk GO was also supported by Romero et al. [139], whose work mainly focused on different switching mechanisms of GO memristive devices.

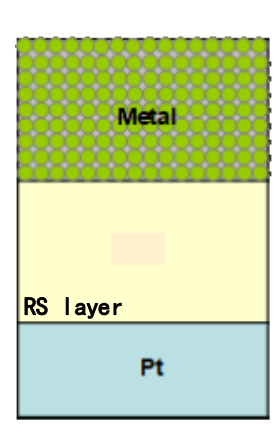

virgin stot.

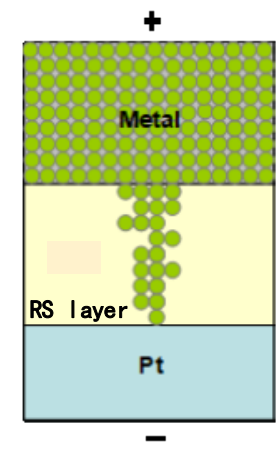

ON stoto

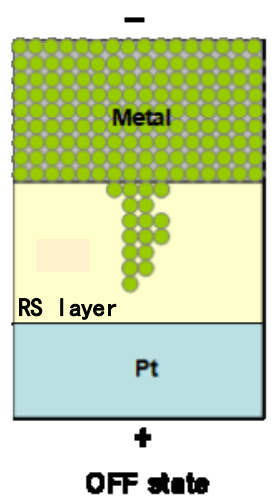

Figure 8. Schematic diagram for the mechanism of the resistive switching effect in metal/GO/Pt memory cells [132].

(a)

(1)

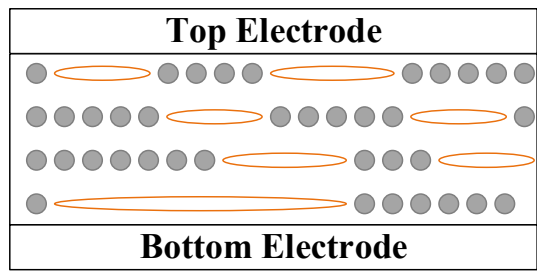

(2)

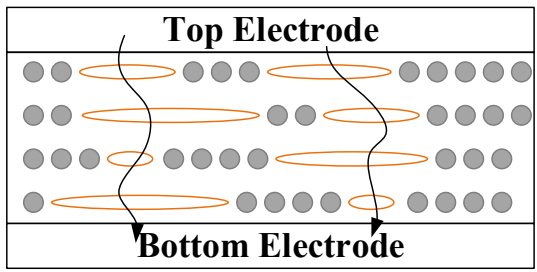

(b)

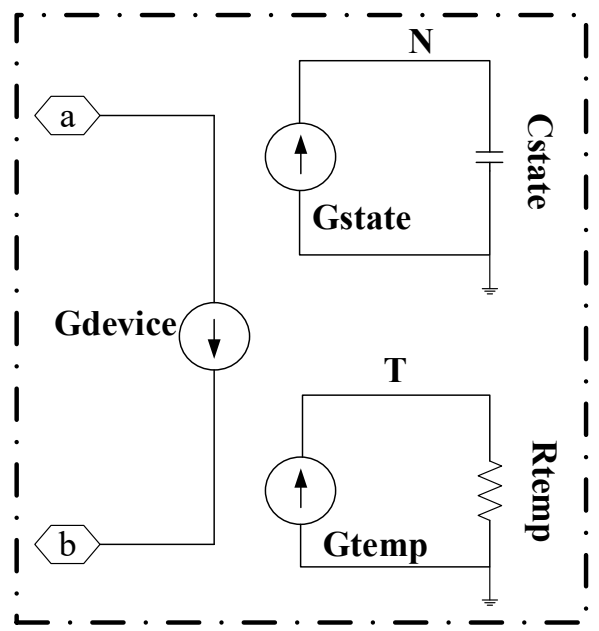

Figure 9. (a) Illustration of transport mechanism in GO-RRAM based on hybridization state modulation; (b) SPICE macro implementation of the compact hybridization state modulation model. 
In addition, some other research teams aimed at an investigation of the contacting relationship between the GRM layer and electrode layer or other RS layers, mainly related to single-layer graphene (SLG) or multi-layer graphene (MLG) interlayers applied in RRAM devices with metal-oxide (M-O) thin films [139,152-156]. In the literature review, it is noteworthy that Chen et al. presented a TiN/SLG/ $\mathrm{HfO}_{2} / \mathrm{Pt}$ RRAM device with an SLG interlayer [152]. The $\mathrm{HfO}_{2}$ layer was fabricated by ALD, and the SLG layer was transferred onto the RS layer with oxygen plasma etching. The inserted SLG layer increased the resistance value at LRS $(>1 \mathrm{M} \Omega)$ of the $\mathrm{HfO}_{2}$-based RRAM device due to its high out-of-plane resistance, which reduced the reset current 22-fold while decreasing the programming power consumption 47-fold. With the measurement results from Raman mapping illustrated in Figure 10b, obvious changes in the SLG interlayer in both the D-band and the G-band signals can be observed, which indicate that oxygen drifting from the $\mathrm{M}-\mathrm{O}$ layer might interact with the graphene. Chen's work also illustrated that the interface engineering design is very essential for the selection of RS and electrode materials for RRAM devices.
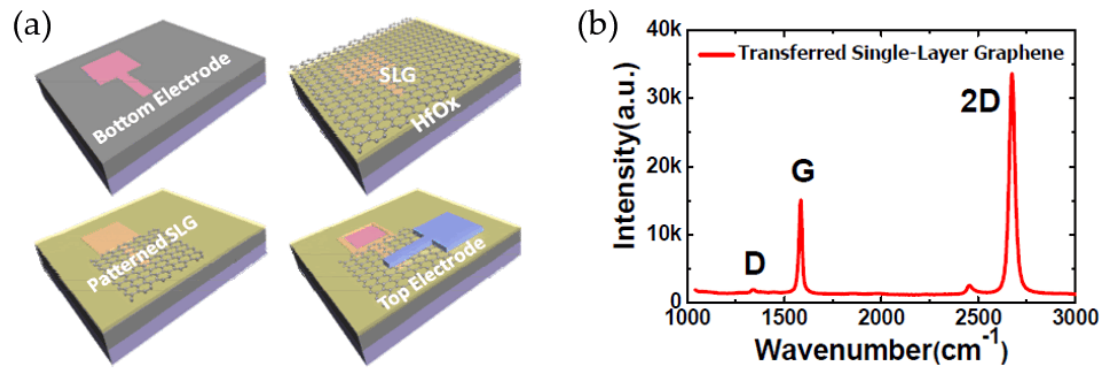

Figure 10. (a) Fabrication process of $\mathrm{HfO}_{x}$-based RRAM device with single-layer graphene (SLG) interlayer and (b) Raman spectroscopy data of transferred SLG layer [152].

\section{Application of Graphene-Based Memristors in Flexible Electronics}

As one of most representative and competitive graphene-based materials, GO received considerable attention in the industry of large-area flexible electronic devices due to its promising potential for next-generation information storage [156-163]. GO can be dispersed in a variety of solvents, which permits compatible processes with a wide range of commercially available flexible substrates. With various technologies like spin coating [164-166], drop casting [167-169], dip coating [170-172], and inkjet printing $[157,173,174]$, GO dielectric layers can be deposited onto flexible substrates like polyethylene terephthalate (PET), polyether sulfone (PES), and polyimide [175-180]. In addition, the thickness of a single atomic layer and the excellent dispersibility in various solvents result in GO having enhanced compatibility with different commercial substrates [181-183]. Table 5 demonstrates several samples of graphene-based memristive devices with electrical performance.

Table 5. Flexible memristive devices with GO-based materials [121,124,145,163,184-187].

\begin{tabular}{lllllll}
\hline Structure & $\begin{array}{l}\text { Flexible } \\
\text { Substrate }\end{array}$ & $\begin{array}{l}\text { Fabrication Method } \\
\text { of RS Layer }\end{array}$ & $\begin{array}{l}\text { On/Off } \\
\text { Ratio }\end{array}$ & $\begin{array}{l}\text { Retention } \\
\text { Time (s) }\end{array}$ & $\begin{array}{l}\text { Endurance } \\
\text { Cycles }\end{array}$ & $\begin{array}{l}\text { Memory } \\
\text { Type }\end{array}$ \\
\hline Al/GO/ITO & PET & Spin coating & $10^{3}$ & $10^{7}$ & 100 & RRAM \\
Al/CMC-GO/Al & PET & Spin coating & $10^{5}$ & 2000 & N.A. & RRAM \\
Al/GO/Al & PES & Coating & 200 & $10^{4}$ & N.A. & RRAM \\
Al/GO/ITO & PET & Spin coating & 280 & $10^{4}$ & 120 & RRAM \\
Al/GO/Al & PES & Spin casting & $10^{3}$ & $10^{5}$ & 100 & RRAM \\
Al/Au-rGO/ITO & PET & Spin casting & $10^{3}$ & $10^{5}$ & N.A. & RRAM \\
hrGO/lrGO/hrGO & PET & Spin coating & $10^{3}$ & 1000 & N.A. & RRAM \\
Al/GO/ITO & PET & Drop casting & 30 & $10^{4}$ & N.A. & RRAM \\
\hline
\end{tabular}


According to the statistical results from Table 5, the most popular RS medium of flexible GRM-based RRAM devices is GO, whereas Al and ITO are considered preferable for the role of TE and $\mathrm{BE}$, respectively. The structure of an $\mathrm{Al} / \mathrm{GO} / \mathrm{ITO} /$ flexible substrate is even more popular.

Wang et al. reported a GO-RRAM device with the structure of Al/GO/ITO/PET, as illustrated in Figure 11a. The GO thin film was spin-coated onto the ITO substrate. According to their perspective, the speed of rotation process and the GO precursor solution concentration determined the growth rate and thickness of the GO thin film. They controlled the growth rate at around $0.4 \mathrm{~nm}$ per GO drop, and the rotation speed was $1000 \mathrm{rpm}$. The fabricated device could operate with an operation voltage lower than $\sim 2.5 \mathrm{~V}$ and the on/off ratio was about $\sim 280$. The retention was higher than $10^{4} \mathrm{~s}$, and the endurance cycles were more than 110. In addition, with the pulse behavior measurement, they also found that the resistance state switching from LRS to HRS could appear with a 100-ns pulse width, while the switching process from HRS to LRS could only be achieved with a 100- $\mu$ s pulse width [145].

(a)

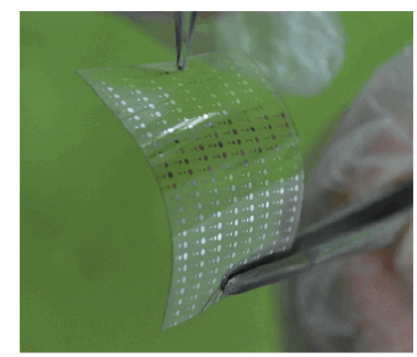

(b)

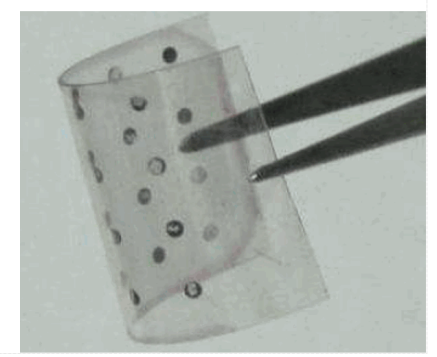

Figure 11. Illustration of GO-based flexible RRAM devices with structures of (a) $\mathrm{Al} / \mathrm{GO} / \mathrm{ITO} / \mathrm{PET}$ and (b) Al/Au/rGO/PVA NP/ITO/PET [148].

Another RRAM device based on an $\mathrm{Al} / \mathrm{rGO} / \mathrm{ITO} /$ flexible substrate with a combination of $\mathrm{Au}$ nanoparticles (Au NPs) and polyvinyl alcohol (PVA) was reported by Midya et al. The Au/rGO/PVA dielectric layer was fabricated with a solution-processed method. In this work, in order to prevent Au NP coagulation, GO flakes fabricated via a modified Hummer's method and $\mathrm{HAuCl}_{4}$ solution were homogenized into the PVA solution. With a series of chemical treatments, the hybrid thin film was spin-coated onto the ITO/PET substrate. The fabricated device demonstrated a bipolar RS performance with $\sim 1-\mathrm{V}$ operation voltage in the SET process and a $\sim 10^{3}$ on/off ratio. The resistance distribution result indicated that the device exhibited better performance when the resistance state switched to LRS [185].

Apart from Wang and Midya et al., Hong et al. also reported a GO-RRAM device with the same structure, which was a transparent Al/GO/ITO device with a flexible PET substrate. Different GO dielectric layers with three thicknesses $(\sim 15, \sim 30$, and $\sim 45 \mathrm{~nm})$ were also fabricated with a spin-coating process, and the device exhibited enhanced performance with a high on/off ratio, low set/reset voltage, and excellent data retention. With the statistical results of GO thickness dependence on fabricated devices, an RRAM device with a 30-nm GO layer exhibited the lowest operation voltage $(\sim 2 \mathrm{~V})$ and the highest on/off ratio $\left(\sim 10^{3}\right)$, which indicated that the 30-nm-thick GO thin film might be an optimistic choice for their investigation. It is noted that the fabricated flexible GO memory device with $30 \mathrm{~nm}$ thickness demonstrated excellent RS performance with no degradation, even when the substrate was bent down to 4-mm radius 1000 times [121].

Although the Al/GO/ITO structure received substantial attention, another kind of structure with $\mathrm{Al} / \mathrm{GO} / \mathrm{Al}$ on a flexible substrate was also investigated. Our previous work demonstrated an $\mathrm{Al} / \mathrm{GO} / \mathrm{Si} / \mathrm{Al}$ structure RRAM device with a spin-coated GO dielectric layer. The device could operate with an operation voltage lower than $2 \mathrm{~V}$, and the on/off ratio was around $10^{3}$. The retention performance indicated that the device could sustain data over $10^{4} \mathrm{~s}$, and its endurance cycles exceeded 100 . The GO suspension liquid of graphite oxide powder and ethyl alcohol was spin-coated onto the substrate, 
which indicates the great potential of a solution-processed GO dielectric layer to be deposited onto a flexible substrate [19].

As illustrated in Figure 12, Jeong et al. reported an RRAM device with an Al/GO/Al/PES structure, which was fabricated with a spin-casted GO thin film. The fabricated device could complete the switching process with an operation voltage lower than $2 \mathrm{~V}$ and an on/off ratio higher than $10^{3}$. Figure $12 \mathrm{~b}$ demonstrates the measurement effect of device performance induced by bending times and radius, which indicates that the $\mathrm{Al} / \mathrm{GO} / \mathrm{Al} / \mathrm{PES}$ structure is suitable for flexible $\mathrm{NVM}$ devices. According to their perspective, the spin-casting process with enough simplicity and scalability can be a choice for the fabrication of large-area uniform GO thin films, whereas the final goal is to allow the fabricated GO thin film to be transferred to all kinds of flexible substrates. Furthermore, the spin-coating technology applied to practical devices might have great potential for integration with current standard COMS processes, in order to provide a contribution during the development of NVM devices [124].
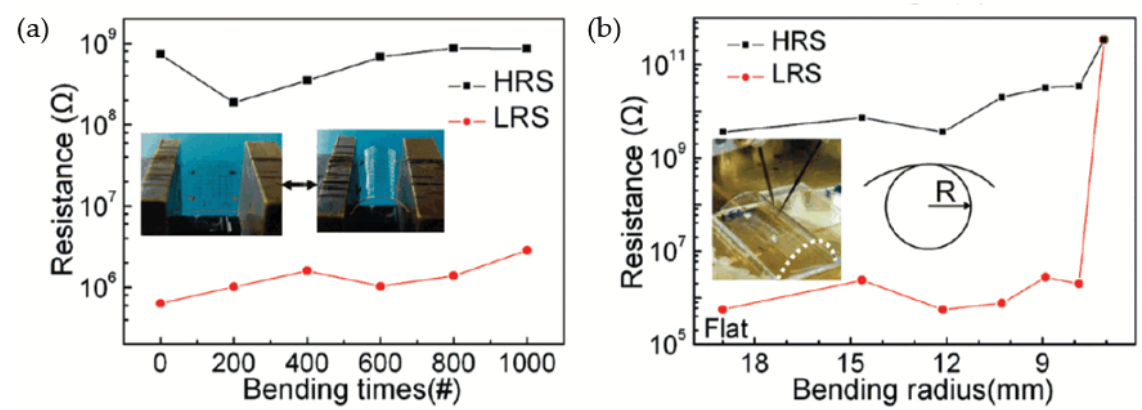

Figure 12. Measurement of bending effect for $\mathrm{Al} / \mathrm{GO} / \mathrm{Al} / \mathrm{PES}$ RRAM devices. (a) The relationship between on/off ratio and bending times and (b) the relationship between on/off ratio and bending radius [124].

Liu et al. illustrated their research on an Al/GO/Al/PET structure RRAM device on PET substrate with a spin-coated GO dielectric layer [163], which showed excellent RS performance with a low operation voltage $(\sim 2 \mathrm{~V})$, high resistance ratio between on and off states $\left(\sim 10^{5}\right)$, and long data retention time ( $2000 \mathrm{~s})$. The formation and the rupture of CFs based on metal ion diffusion near the interface layer between TE and dielectric layer were used to interpret their achievements [132,133,163].

Apart from GO materials, a mixture of graphene-based materials and 2D materials (like $\mathrm{MoS}_{2}$ and h-BN) was also investigated in recent years [188-191]. The surface modification of GO layers in solution through chemical functionalization is expected to play a key role in tailoring the structure, processability, and physicochemical and electronic properties of GO layers. As reported by Wu et al. [188], with vigorous stirring and spin-coating operations for a precursor suspension of $\mathrm{MoS}_{2}$ and GO, they fabricated an RRAM device with a Ti/MoS $2-\mathrm{GO} / \mathrm{ITO} / \mathrm{PET}$ structure. Due to the doping of $\mathrm{MoS}_{2}$, the device worked with a lower operation voltage $(\sim 0.3 \mathrm{~V})$. Their bending test results showed that almost no changes in LRS and HRS could be observed during 200 switching cycles, even with 300 bending cycles, which indicated the enhanced reproducibility of RRAM devices [188]. The electron mobile induced by different energy levels of each layer was used to explain the switching mechanism [188].

\section{Conclusions}

We briefly reviewed recent advances in graphene-based materials used in NVM devices. Reliable systems based on memristors will be a vital technological application in the future development of neuromorphic networks and the AI industry, which are presented with a combined form of RRAM hardware devices and neuromorphic algorithms. Different devices based on graphene-materials mentioned in the recent literature exhibited good switching performance such as low power consumption, enhanced retention and endurance properties, large on/off ratio, and good compatibility with flexible substrates. Despite the great potential of graphene-based materials applied in NVM demonstrated in related research, some limitations cannot be neglected. Firstly, GO as the derivative 
of graphene was used extensively in electronic device research. The occurrence and organization of oxygen functionalities, the intrinsic variability of the GO material chemical structure, and the random distribution of GO flakes during the fabrication and deposition process directly influence the switching behavior of devices. Secondly, many current synthesis technologies of graphene-based materials are not only mature in the commercial market but also limit the development of large-scale production with good uniformity. Thirdly, the reliability performance of devices, in terms of retention and endurance measurements, needs to be evaluated and improved more accurately in order to meet real application demands in commercial products. In addition, although related switching mechanisms were proposed in the recent literature, definitive evidence in their support remains to be provided.

Author Contributions: Conceptualization, Z.S. and C.Z. (Chun Zhao); Methodology, Z.S., C.Z. (Chun Zhao) and Y.Q.; Software, C.Z. (Chun Zhao), C.Z. (Cezhou Zhao) and L.Y.; Validation, C.Z. (Chun Zhao) and C.Z. (Cezhou Zhao); Formal Analysis, Z.S., C.Z. (Chun Zhao), J.W., Y.H. and P.L.; Investigation, Z.S., J.W., Y.H., and P.L.; Resources, Z.S. and C.Z. (Chun Zhao); Data Curation, Z.S., J.W., Y.H. and P.L.; Writing-Original Draft Preparation, Z.S.; Writing-Review \& Editing, Z.S., C.Z. (Chun Zhao) and I.Z.M.; Visualization, Z.S. and C.Z. (Chun Zhao); Supervision, C.Z. (Chun Zhao), C.Z. (Cezhou Zhao), I.Z.M. and L.Y.; Project Administration, C.Z. (Chun Zhao) and C.Z. (Cezhou Zhao); Funding Acquisition, C.Z. (Chun Zhao), C.Z. (Cezhou Zhao) and I.Z.M. All authors have read and agreed to the published version of the manuscript.

Funding: This research was funded in part by the Natural Science Foundation of the Jiangsu Higher Education Institutions of China Program (19KJB510059), the Suzhou Science and Technology Development Planning Project: Key Industrial Technology Innovation (SYG201924), and the Key Program Special Fund in XJTLU (KSF-P-02, KSF-T-03, KSF-A-04, KSF-A-05, KSF-A-07).

Acknowledgments: The author Ivona Z. Mitrovic acknowledges the British Council UKIERI project no. IND/CONT/G/17-18/18.

Conflicts of Interest: The authors declare no conflict of interest.

\section{References}

1. Bertolazzi, S.; Bondavalli, P.; Roche, S.; San, T.; Choi, S.Y.; Colombo, L.; Bonaccorso, F.; Samori, P. Nonvolatile Memories Based on Graphene and Related 2D Materials. Adv. Mater. 2019, 31, e1806663. [CrossRef]

2. Wang, X.; Xie, W.; Xu, J.B. Graphene based non-volatile memory devices. Adv. Mater. 2014, 26, 5496-5503. [CrossRef]

3. Zhang, S.R.; Zhou, L.; Mao, J.Y.; Ren, Y.; Yang, J.Q.; Yang, G.H.; Zhu, X.; Han, S.T.; Roy, V.A.L.; Zhou, Y. Artificial Synapse Emulated by Charge Trapping-Based Resistive Switching Device. Adv. Mater. Technol. 2018, 4. [CrossRef]

4. Tan, Y.F.; Su, Y.T.; Chen, M.C.; Chang, T.C.; Tsai, T.M.; Tseng, Y.T.; Yang, C.C.; Zheng, H.X.; Chen, W.C.; Lin, C.C.; et al. The influence of temperature on set voltage for different high resistance state in 1T1R devices. Appl. Phys. Express 2019, 12, 024004. [CrossRef]

5. Irshad, M.S.; Abbas, A.; Qazi, H.H.; Aziz, M.H.; Shah, M.; Ahmed, A.; Idrees, M. Role of point defects in hybrid phase $\mathrm{TiO}_{2}$ for resistive random-access memory (RRAM). Mater. Res. Express 2019, 6, 076326. [CrossRef]

6. $\quad$ Lin, C.C.; Chen, P.H.; Chen, M.C.; Chang, T.C.; Lin, C.Y.; Zheng, H.X.; Chen, C.K.; Huang, W.C.; Chen, W.C.; Huang, H.C.; et al. Investigating Material Changes at Different Gadolinium Doping Power Levels in Indium-Tin Oxide Intended for Use as an Insulator in Resistive Switching Memory. IEEE Trans. Electron. Devices 2019, 66, 2595-2599. [CrossRef]

7. Qiu, J.T.; Samanta, S.; Dutta, M.; Ginnaram, S.; Maikap, S. Controlling Resistive Switching by Using an Optimized $\mathrm{MoS}_{2}$ Interfacial Layer and the Role of Top Electrodes on Ascorbic Acid Sensing in $\mathrm{TaO}_{\mathrm{x}}$-Based RRAM. Langmuir 2019, 35, 3897-3906. [CrossRef] [PubMed]

8. Liu, S.; Dong, S.; Jin, H.; Huang, S.; Wang, X.; Luo, J. Significant Effects of Electrode Metal Work Function on Resistive Memory Devices with Gelatin Biodielectric Layer. J. Electrochem. Soc. 2018, 165, G90-G95. [CrossRef]

9. Shen, Z.J.; Zhao, C.; Zhao, C.Z.; Mitrovic, I.Z.; Yang, L.; Xu, W.Y.; Lim, E.G.; Luo, T.; Huang, Y.B. Characteristics of $\mathrm{Ni} / \mathrm{AlO}_{x} / \mathrm{Pt}$ RRAM devices with various dielectric fabrication temperatures. In Proceedings of the 2019 International Conference on IC Design and Technology (ICICDT), Suzhou, China, 17-19 June 2019; pp. 1-4. 
10. Liu, C.Y.; Tsai, Y.Y.; Fang, W.T.; Wang, H.Y. Resistive Switching Characteristics of a SiO ${ }_{x}$ Layer with $\mathrm{CF}_{4} \mathrm{Plasma}$ Treatment. J. Nanomater. 2014, 2014, 1-5.

11. Qi, M.; Guo, C.; Zeng, M. Oxygen Vacancy Kinetics Mechanism of the Negative Forming-Free Process and Multilevel Resistance Based on Hafnium Oxide RRAM. J. Nanomater. 2019, 2019, 1-9. [CrossRef]

12. Wang, E.; Dong, Y.; Islam, M.D.Z.; Yu, L.; Liu, F.; Chen, S.; Qi, X.; Zhu, Y.; Fu, Y.; Xu, Z.; et al. Effect of graphene oxide-carbon nanotube hybrid filler on the mechanical property and thermal response speed of shape memory epoxy composites. Compos. Sci. Technol. 2019, 169, 209-234. [CrossRef]

13. Liu, Y.; Yin, J.; Liu, X.; Zhao, X.; Chen, M.; Li, J.; Zhao, H.; Zhu, C.; Su, B. Fabrication of polymer composite films with carbon composite nanofibers doped MWNTs-OH for multilevel memory device application. Compos. B Eng. 2019, 156, 252-270. [CrossRef]

14. Rowlands, G.E.; Ryan, C.A.; Ye, L.; Rehm, L.; Pinna, D.; Kent, A.D.; Ohki, T.A. A cryogenic spin-torque memory element with precessional magnetization dynamics. Sci. Rep. 2019, 9, 803. [CrossRef] [PubMed]

15. Zhang, H.; Kang, W.; Cao, K.; Wu, B.; Zhang, Y.; Zhao, W. Spintronic Processing Unit in Spin Transfer Torque Magnetic Random Access Memory. IEEE Trans. Electron. Devices 2019, 66, 2017-2022. [CrossRef]

16. Mukherjee, B. Resistive Switching and Nonvolatile Memory in $\mathrm{TiO}_{2} / \mathrm{CuPc}$ Nanocomposite Devices. J. Electron. Mater. 2019, 48, 2131-2132. [CrossRef]

17. Yu, J.; Xu, X.; Gong, T.; Luo, Q.; Dong, D.; Yuan, P.; Tai, L.; Yin, J.; Zhu, X.; Wu, X.; et al. Suppression of Filament Overgrowth in Conductive Bridge Random Access Memory by $\mathrm{Ta}_{2} \mathrm{O}_{5} / \mathrm{TaO}_{\mathrm{x}}$ Bi-Layer Structure. Nanoscale Res. Lett. 2019, 14, 111-116. [CrossRef]

18. Yun, H.-W.; Woo, H.K.; Oh, S.J.; Hong, S.-H. Flexible NiO nanocrystal-based resistive memory device fabricated by low-temperature solution-process. Curr. Appl. Phys. 2020, 20, 288-292. [CrossRef]

19. Qi, Y.F.; Shen, Z.J.; Zhao, C.; Mitrovic, I.Z.; Xu, W.Y.; Lim, E.G.; Yang, L.; He, J.H.; Luo, T.; Huang, Y.B.; et al. Resistive switching behavior of solution-processed $\mathrm{AlO}_{\mathrm{x}}$ and $\mathrm{GO}$ based RRAM at low temperature. Solid State Electron. 2019. [CrossRef]

20. Kang, K.; Ahn, H.; Song, Y.; Lee, W.; Kim, J.; Kim, Y.; Yoo, D.; Lee, T. High-Performance Solution-Processed Organo-Metal Halide Perovskite Unipolar Resistive Memory Devices in a Cross-Bar Array Structure. Adv. Mater. 2019, 31, 1804841. [CrossRef]

21. Das, U.; Bhattacharjee, S.; Mahato, B.; Prajapat, M.; Sarkar, P.; Roy, A. Uniform, large-scale growth of $\mathrm{WS}_{2}$ nanodomains via CVD technique for stable non-volatile RRAM application. Mater. Sci. Semicond. Process. 2020, 107, 104837. [CrossRef]

22. Neumann, C.M.; Okabe, K.L.; Yalon, E.; Grady, R.W.; Wong, H.S.P.; Pop, E. Engineering thermal and electrical interface properties of phase change memory with monolayer $\mathrm{MoS}_{2}$. Appl. Phys. Lett. 2019, 114, 082103. [CrossRef]

23. Zheng, Y.; Fischer, A.; Sawatzki, M.; Doan, D.H.; Liero, M.; Glitzky, A.; Reineke, S.; Mannsfeld, S.C.B. Introducing pinMOS Memory: A Novel, Nonvolatile Organic Memory Device. Adv. Funct. Mater. 2019. [CrossRef]

24. Casula, G.; Busby, Y.; Franquet, A.; Spampinato, V.; Houssiau, L.; Bonfiglio, A.; Cosseddu, P. A flexible organic memory device with a clearly disclosed resistive switching mechanism. Org. Electron. 2019, 64, 209-215. [CrossRef]

25. Chiu, U.T.; Lee, B.F.; Hu, S.K.; Yu, T.F.; Lee, W.Y.; Chao, L. Graphene Memory Based on a Tunable Nanometer-Thin Water Layer. J. Phys. Chem. C 2019, 123, 10842-10848. [CrossRef]

26. Guo, F.; Zheng, X.; Liang, C.; Jiang, Y.; Xu, Z.; Jiao, Z.; Liu, Y.; Wang, H.T.; Sun, H.; Ma, L.; et al. Millisecond Response of Shape Memory Polymer Nanocomposite Aerogel Powered by Stretchable Graphene Framework. ACS Nano 2019, 13, 5549-5558. [CrossRef]

27. Yan, Y.; Xia, H.; Qiu, Y.; Xu, Z.; Ni, Q.Q. Multi-layer graphene oxide coated shape memory polyurethane for adjustable smart switches. Compos. Sci. Technol. 2019, 172, 108-116. [CrossRef]

28. Liu, J.; Zeng, Z.; Cao, X.; Lu, G.; Wang, L.H.; Fan, Q.L.; Huang, W.; Zhang, H. Preparation of $\mathrm{MoS}_{2}$-polyvinylpyrrolidone nanocomposites for flexible nonvolatile rewritable memory devices with reduced graphene oxide electrodes. Small 2012, 8, 3517-3522. [CrossRef]

29. Park, J.H.; Shin, M.H.; Yi, J.S. The Characteristics of Transparent Non-Volatile Memory Devices Employing Si-Rich $\mathrm{SiO}_{x}$ as a Charge Trapping Layer and Indium-Tin-Zinc-Oxide. Nanomaterials (Basel) 2019, 9, 784. [CrossRef] 
30. Feng, J.; Liu, Z.J.; Zhang, D.Q.; He, Z.; Tao, Z.C.; Guo, Q.G. Phase change materials coated with modified graphene-oxide as fillers for silicone rubber used in thermal interface applications. New Carbon Mater. 2019, 34, 188-195. [CrossRef]

31. Seo, S.; Lim, J.; Lee, S.; Alimkhanuly, B.; Kadyrov, A.; Jeon, D.; Lee, S. Graphene-Edge Electrode on a Cu-Based Chalcogenide Selector for 3D Vertical Memristor Cells. ACS Appl. Mater. Interfaces 2019, 11, 43466-43472. [CrossRef]

32. Hyun, W.J.; Secor, E.B.; Kim, C.H.; Hersam, M.C.; Francis, L.F.; Frisbie, C.D. Scalable, Self-Aligned Printing of Flexible Graphene Micro-Supercapacitors. Adv. Energy Mater. 2017, 7, 8. [CrossRef]

33. Geim, A.K.; Novoselo, K.S. The rise of graphene. Nat. Mater. 2007, 6, 183-191. [CrossRef] [PubMed]

34. Rafiee, R.; Eskandariyun, A. Estimating Young's modulus of graphene/polymer composites using stochastic multi-scale modeling. Compos. B Eng. 2019, 173, 106842. [CrossRef]

35. Kashani, H.; Ito, Y.; Han, J.; Liu, P.; Chen, M. Extraordinary tensile strength and ductility of scalable nanoporous graphene. Sci. Adv. 2019, 5, eaat6951. [CrossRef] [PubMed]

36. Leong, W.S.; Wang, H.; Yeo, J.; Martin-Martinez, F.J.; Zubair, A.; Shen, P.C.; Mao, Y.; Palacios, T.; Buehler, M.J.; Hong, J.Y.; et al. Paraffin-enabled graphene transfer. Nat. Commun. 2019, 10, 867-874. [CrossRef] [PubMed]

37. Liang, C.; Qiu, H.; Han, Y.; Gu, H.; Song, P.; Wang, L.; Kong, J.; Cao, D.; Gu, J. Superior electromagnetic interference shielding 3D graphene nanoplatelets/reduced graphene oxide foam/epoxy nanocomposites with high thermal conductivity. J. Mater. Chem. C 2019, 7, 2725-2733. [CrossRef]

38. Wang, E.; Wu, Y.; Islam, M.Z.; Dong, Y.; Zhu, Y.; Liu, F.; Fu, Y.; Xu, Z.; Hu, N. A novel reduced graphene oxide/epoxy sandwich structure composite film with thermo-, electro- and light-responsive shape memory effect. Mater. Lett. 2019, 238, 54-57. [CrossRef]

39. Strauss, V.; Marsh, K.; Kowal, M.D.; El-Kady, M.; Kaner, R.B. A Simple Route to Porous Graphene from Carbon Nanodots for Supercapacitor Applications. Adv. Mater. 2018, 30, 1704449. [CrossRef]

40. Tahernejad-Javazmi, F.; Shabani-Nooshabadi, M.; Karimi-Maleh, H. 3D reduced graphene oxide/FeNi ${ }_{3}$-ionic liquid nanocomposite modified sensor; an electrical synergic effect for development of tert-butylhydroquinone and folic acid sensor. Compos. B Eng. 2019, 172, 666-670. [CrossRef]

41. Pang, Y.; Zhang, K.; Yang, Z.; Jiang, S.; Ju, Z.; Li, Y.; Wang, X.; Wang, D.; Jian, M.; Zhang, Y.; et al. Epidermis Microstructure Inspired Graphene Pressure Sensor with Random Distributed Spinosum for High Sensitivity and Large Linearity. ACS Nano 2018, 12, 2346-2354. [CrossRef]

42. Zhang, Y.; An, Y.; Wu, L.; Chen, H.; Li, Z.; Dou, H.; Murugadoss, V.; Fan, J.; Zhang, X.; Mai, X.; et al. Metal-free energy storage systems: Combining batteries with capacitors based on a methylene blue functionalized graphene cathode. J. Mater. Chem. A 2019, 7, 19668-19675. [CrossRef]

43. Li, X.; Zhi, L. Graphene hybridization for energy storage applications. Chem. Soc. Rev. 2018, 47, 3189-3216. [CrossRef] [PubMed]

44. Sanchez-Hidalgo, R.; Blanco, C.; Menendez, R.; Verdejo, R.; Lopez-Manchado, M.A. Multifunctional Silicone Rubber Nanocomposites by Controlling the Structure and Morphology of Graphene Material. Polymers (Basel) 2019, 11, 449. [CrossRef]

45. Hong, A.J.; Song, E.B.; Yu, H.S.; Allen, M.J.; Kim, J.; Fowler, J.D.; Wassei, J.K. GrapheneFlash Memory. ACS Nano 2011, 5, 7812-7817. [CrossRef]

46. Cunning, B.V.; Wang, B.; Shin, T.J.; Ruoff, R.S. Structure-directing effect of single crystal graphene film on polymer carbonization and graphitization. Mater. Horiz. 2019, 6, 796-801. [CrossRef]

47. Cheng, Y.; Bi, H.; Che, X.; Li, D.; Ji, W.; Huang, F. Suppression of graphene nucleation by plasma treatment of $\mathrm{Cu}$ foil for the rapid growth of large-size single-crystal graphene. Carbon 2019, 147, 51-57. [CrossRef]

48. Yang, Q.; Zhang, Z.; Zhu, W.; Wang, G. Growth of Large-Area High-Quality Graphene on Different Types of Copper Foil Preannealed under Positive Pressure $\mathrm{H}_{2}$ Ambience. ACS Omega 2019, 4, 5165-5171. [CrossRef] [PubMed]

49. Deng, B.; Liu, Z.; Peng, H. Toward Mass Production of CVD Graphene Films. Adv. Mater. 2019, 31, e1800996. [CrossRef] [PubMed]

50. Choi, Y.S.; Yeo, C.S.; Kim, S.J.; Lee, J.Y.; Kim, Y.; Cho, K.R.; Ju, S.; Hong, B.H.; Park, S.Y. Multifunctional reduced graphene oxide-CVD graphene core-shell fibers. Nanoscale 2019, 11, 12637-12642. [CrossRef]

51. Kim, K.; Lee, H.B.; Johnson, R.W.; Tanskanen, J.T.; Liu, N.; Kim, M.G.; Pang, C.; Ahn, C.; Bent, S.F.; Bao, Z. Selective metal deposition at graphene line defects by atomic layer deposition. Nat. Commun. 2014, 5, 4781-4789. [CrossRef] 
52. Van Veldhoven, Z.A.; Alexander-Webber, J.A.; Sagade, A.A.; Braeuninger-Weimer, P.; Hofmann, S. Electronic properties of CVD graphene: The role of grain boundaries, atmospheric doping, and encapsulation by ALD. Phys. Status Solidi B 2016, 253, 2321-2325. [CrossRef]

53. Liang, T.; Habib, M.R.; Kong, Y.; Cai, Y.; Chen, H.; Fujita, D.; Lin, C.-T.; Liu, Y.; Yu, C.; Su, H.; et al. Elucidation of heterogeneous graphene nucleation and growth through $\mathrm{Cu}$ surface engineering. Carbon 2019, 147, 120-125. [CrossRef]

54. Farajian, A.A.; Mortezaee, R.; Osborn, T.H.; Pupysheva, O.V.; Wang, M.; Zhamu, A.; Jang, B.Z. Multiscale molecular thermodynamics of graphene-oxide liquid-phase exfoliation. Phys. Chem. Chem. Phys. 2019, 21, 1761-1772. [CrossRef] [PubMed]

55. Cai, H.; Ma, G.; He, Y.; Lu, L.; Zhang, J.; Wang, H. Compact pure phase CsPbBr 3 perovskite film with significantly improved stability for high-performance memory. Ceram. Int. 2019, 45, 1150-1155. [CrossRef]

56. Chen, D.; Wang, F.; Li, Y.; Wang, W.W.; Huang, T.X.; Li, J.F.; Novoselov, K.S.; Tian, Z.Q.; Zhan, D. Programmed electrochemical exfoliation of graphite to high quality graphene. Chem. Commun. (Camb.) 2019, 55, 3379-3382. [CrossRef] [PubMed]

57. Ejigu, A.; Le Fevre, L.W.; Fujisawa, K.; Terrones, M.; Forsyth, A.J.; Dryfe, R.A.W. Electrochemically Exfoliated Graphene Electrode for High-Performance Rechargeable Chloroaluminate and Dual-Ion Batteries. ACS Appl. Mater. Interfaces 2019, 11, 23261-23270. [CrossRef]

58. Zhang, L.; Gong, T.; Wang, H.; Guo, Z.; Zhang, H. Memristive devices based on emerging two-dimensional materials beyond graphene. Nanoscale 2019, 11, 12413-12435. [CrossRef]

59. McLean, B.; Webber, G.B.; Page, A.J. Boron Nitride Nanotube Nucleation via Network Fusion during Catalytic Chemical Vapor Deposition. J. Am. Chem. Soc. 2019, 141, 13385-13393. [CrossRef]

60. Zhang, Y.; Yao, Y.; Sendeku, M.G.; Yin, L.; Zhan, X.; Wang, F.; Wang, Z.; He, J. Recent Progress in CVD Growth of 2D Transition Metal Dichalcogenides and Related Heterostructures. Adv. Mater. 2019, 31, e1901694. [CrossRef]

61. Hong, Y.L.; Seo, T.H.; Jang, H.; Kim, Y.K. The Effect of Oxidative Debris on the Laser Desorption/Ionization Efficiency of Graphene Oxide Derivatives for Mass Spectrometric Analysis of Small Molecules and Synthetic Polymers. Anal. Sci. 2019, 35, 1097-1102. [CrossRef]

62. Tang, H.; Tao, J.; Ruzsinszky, A.; Perdew, J.P. van der Waals Correction to the Physisorption of Graphene on Metal Surfaces. J. Phys. Chem. C 2019, 123, 13748-13757. [CrossRef]

63. Jin, B.; Xiong, D.B.; Tan, Z.; Fan, G.; Guo, Q.; Su, Y.; Li, Z.; Zhang, D. Enhanced corrosion resistance in metal matrix composites assembled from graphene encapsulated copper nanoflakes. Carbon 2019, 142, 482-490. [CrossRef]

64. Chuang, C.; Mineharu, M.; Matsunaga, M.; Liu, C.W.; Wu, B.Y.; Kim, G.H.; Watanabe, K.; Taniguchi, T.; Liang, C.T.; Aoki, N. Conductance interference effects in an electron-beam-resist-free chemical vapor deposition graphene device sandwiched between two h-BN sheets. Carbon 2019, 154, 238-243. [CrossRef]

65. Şar, H.; Özden, A.; Demiroğlu, İ.; Sevik, C.; Perkgoz, N.K.; Ay, F. Long-Term Stability Control of CVD-Grown Monolayer $\mathrm{MoS}_{2}$. Phys. Status Solidi RRL Rapid Res. Lett. 2019, 13, 1800687. [CrossRef]

66. Meng, Q.; Deng, B.; Zhang, H.; Wang, B.; Zhang, W.; Wen, Y.; Ming, H.; Zhu, X.; Guan, Y.; Xiang, Y.; et al. Heterogeneous nucleation and growth of electrodeposited lithium metal on the basal plane of single-layer graphene. Energy Storage Mater. 2019, 16, 419-425. [CrossRef]

67. Qiao, Y.; Li, X.; Hirtz, T.; Deng, G.; Wei, Y.; Li, M.; Ji, S.; Wu, Q.; Jian, J.; Wu, F.; et al. Graphene-based wearable sensors. Nanoscale 2019, 11, 18923-18945. [CrossRef]

68. Ott, S.; Wolff, N.; Rashvand, F.; Rao, V.J.; Zaumseil, J.; Backes, C. Impact of the $\mathrm{MoS}_{2}$ Starting Material on the Dispersion Quality and Quantity after Liquid Phase Exfoliation. Chem. Mater. 2019, 31, 8424-8431. [CrossRef]

69. Zhu, X.; Yang, J.; She, X.; Song, Y.; Qian, J.; Wang, Y.; Xu, H.; Li, H.; Yan, Q. Rapid synthesis of ultrathin 2D materials through liquid-nitrogen and microwave treatments. J. Mater. Chem. A 2019, 7, 5209-5213. [CrossRef]

70. Contreras-Pereda, N.; Hayati, P.; Suarez-Garcia, S.; Esrafili, L.; Retailleau, P.; Benmansour, S.; Novio, F.; Morsali, A.; Ruiz-Molina, D. Delamination of 2D coordination polymers: The role of solvent and ultrasound. Ultrason. Sonochem. 2019, 55, 186-195. [CrossRef]

71. Yin, X.; Li, Y.; Meng, H.; Wu, W. Surface functionalization of bulk $\mathrm{MoS}_{2}$ sheets for efficient liquid phase exfoliation in polar micromolecular solvents. Appl. Surf. Sci. 2019, 486, 362-370. [CrossRef] 
72. Omari, I.; Randhawa, P.; Randhawa, J.; Yu, J.; McIndoe, J.S. Structure, Anion, and Solvent Effects on Cation Response in ESI-MS. J. Am. Soc. Mass Spectrom. 2019, 30, 1750-1757. [CrossRef]

73. Long, Y.; Wu, L.; Pan, F.; Zhang, Z.; Yang, M.; Tang, A.; Zhang, G.; Liu, L.; Atrens, A. A Graphene Spin Coatings for Cost-Effective Corrosion Protection for the Magnesium Alloy AZ31. J. Nanosci. Nanotechnol. 2019, 19, 105-111. [CrossRef]

74. Liu, F.; Qiu, X.; Xu, J.; Huang, J.; Chen, D.; Chen, G. High conductivity and transparency of graphene-based conductive ink: Prepared from a multi-component synergistic stabilization method. Prog. Org. Coat. 2019, 133, 125-130. [CrossRef]

75. Kim, H.; Lee, S.; Kim, H. Electrical Heating Performance of Electro-Conductive Para-aramid Knit Manufactured by Dip-Coating in a Graphene/Waterborne Polyurethane Composite. Sci. Rep. 2019, 9, 1511. [CrossRef] [PubMed]

76. Tas, M.; Altin, Y.; Bedeloglu, A. Graphene and graphene oxide-coated polyamide monofilament yarns for fiber-shaped flexible electrodes. J. Text. Inst. 2018, 110, 67-73. [CrossRef]

77. Mitoma, N.; Yano, Y.; Ito, H.; Miyauchi, Y.; Itami, K. Graphene Nanoribbon Dielectric Passivation Layers for Graphene Electronics. ACS Appl. Nano Mater. 2019, 2, 4825-4831. [CrossRef]

78. Puah, P.Y.; Yusoff, U.H.; Lee, P.C.; Moh, P.Y.; How, S.E. Surface characterization, biocompatibility and osteogenic differentiation of drop-casted multilayer graphene oxide film towards human wharton's jelly derived mesenchymal stem cells. Mater. Technol. 2019. [CrossRef]

79. Yang, N.; Cheng, S.; Wu, C.; Jia, R.; Liu, C. Dynamic Behaviors Analysis of a Chaotic Circuit Based on a Novel Fractional-Order Generalized Memristor. Complexity 2019, 2019, 1-15. [CrossRef]

80. Khalil, N.A.; Said, L.A.; Radwan, A.G.; Soliman, A.M. General fractional order mem-elements mutators. Microelectron. J. 2019, 90, 211-221. [CrossRef]

81. Hamsa, S.; Thangadurai, N.; Ananth, A.G. Low power device design application by magnetic tunnel junctions in Magnetoresistive Random Access Memory (MRAM). SN Appl. Sci. 2019, 1, 828-834. [CrossRef]

82. Ansari, M.H.R.; Navlakha, N.; Lin, J.T.; Kranti, A. Improving charge retention in capacitorless DRAM through material and device innovation. Jpn. J. Appl. Phys. 2019, 58, Sbbb03. [CrossRef]

83. Shen, F.; He, Y.; Zhang, J.; Xu, C. Periodic learning-based region selection for energy-efficient MLC STT-RAM cache. J. Supercomput. 2019, 75, 6220-6238. [CrossRef]

84. Mittal, S. Mitigating Read Disturbance Errors in STT-RAM Caches by Using Data Compression. Nanoelectronics 2019. [CrossRef]

85. Liu, C.F.; Tang, X.G.; Wang, L.Q.; Tang, H.; Jiang, Y.P.; Liu, Q.X.; Li, W.H.; Tang, Z.H. Resistive Switching Characteristics of $\mathrm{HfO}_{2}$ Thin Films on Mica Substrates Prepared by Sol-Gel Process. Nanomaterials (Basel) 2019, 9, 1124. [CrossRef] [PubMed]

86. Fu, Y.; Huang, C.C.; Wang, J.C. Nonlinear resistive switching features of rapid-thermal-annealed aluminum nitride dielectrics with modified charge trapping behaviors. Microelectron. Eng. 2019, 216, 111033. [CrossRef]

87. Shih, C.F.; Wu, H.T.; Tsai, W.L.; Leu, C.C. Improvement of resistive memory properties of poly(3,4-ethylenedioxythiophene):poly(styrenesulfonate) $/ \mathrm{CH}_{3} \mathrm{NH}_{3} \mathrm{PbI}_{3}$ based device by potassium iodide additives. J. Alloys Compd. 2019, 783, 478-485. [CrossRef]

88. Cai, C.; Gao, S.; Zhao, P.; Yu, J.; Zhao, K.; Xu, L.; Li, D.; He, Z.; Yang, G.; Liu, T.; et al. SEE Sensitivity Evaluation for Commercial $16 \mathrm{~nm}$ SRAM-FPGA. Electronics 2019, 8, 1531. [CrossRef]

89. Kim, S.M.; Song, B.; Jung, S.-O. Sensing Margin Enhancement Technique Utilizing Boosted Reference Voltage for Low-Voltage and High-Density DRAM. IEEE Trans. Very Large Scale Integr. VLSI Syst. 2019, 27, 2413-2422. [CrossRef]

90. Sakthimurugan, K.; Geetha, K. Designing low power magentic flip flop in $45 \mathrm{~nm}$ FDSOI technology for large scale cluster based engineering application. Clust. Comput. 2018, 22, 6907-6912. [CrossRef]

91. Gomez, R.G.; Bano, E.; Clerc, S. Comparative evaluation of Body Biasing and Voltage Scaling for Low-Power Design on 28nm UTBB FD-SOI Technology. In Proceedings of the 2019 IEEE/ACM International Symposium on Low Power Electronics and Design (ISLPED), Lausanne, Switzerland, 29-31 July 2019; pp. 1-6.

92. Chou, C.H.; Bhuyan, L.N.; Wong, D. $\mu$ DPM: Dynamic Power Management for the Microsecond Era. In Proceedings of the 2019 IEEE International Symposium on High Performance Computer Architecture (HPCA), Washington, DC, USA, 16-20 February 2019; pp. 120-132. 
93. Alanis, A.; Valdés, J.H.; María Guadalupe, N.V.; Lopez, R.; Mendoza, R.; Mathew, A.P.; Díaz de León, R.; Valencia, L. Plasma surface-modification of cellulose nanocrystals: A green alternative towards mechanical reinforcement of ABS. RSC Adv. 2019, 9, 17417-17424. [CrossRef]

94. Gan, L.R.; Wang, Y.R.; Chen, L.; Zhu, H.; Sun, Q.Q. A Floating Gate Memory with U-Shape Recessed Channel for Neuromorphic Computing and MCU Applications. Micromachines (Basel) 2019, 10, 558. [CrossRef] [PubMed]

95. Ooi, P.C.; Mohammad Haniff, M.A.S.; Mohd Razip Wee, M.F.; Goh, B.T.; Dee, C.F.; Mohamed, M.A.; Majlis, B.Y. Electrical transportation mechanisms of molybdenum disulfide flakes-graphene quantum dots heterostructure embedded in polyvinylidene fluoride polymer. Sci. Rep. 2019, 9, 6761. [CrossRef] [PubMed]

96. Kim, B.; Lee, D.; Oh, J.; Yu, H. Scalable disk-based topic modeling for memory limited devices. Inf. Sci. 2020, 516, 353-369. [CrossRef]

97. Qureshi, M.K.; Franceschini, M.; Lastras-Montaño, L.A.; Karidis, J.P. Morphable Memory System A Robust Architecture for Exploiting Multi-Level Phase Change Memories. In Proceedings of the ISCA '10 37th Annual International Symposium on Computer Architecture, Saint-Malo, France, 19-23 June 2010; pp. 153-162.

98. Kim, C.; Kim, D.H.; Jeong, W.; Kim, H.J.; Park, I.H.; Park, H.W.; Lee, J.; Park, J.; Ahn, Y.L.; Lee, J.Y.; et al. A 512-Gb 3-b/Cell 64-Stacked WL 3-D-NAND Flash Memory. IEEE J. Solid-State Circuits 2018, 53, 124-133. [CrossRef]

99. Peng, Y.; Han, G.; Xiao, W.; Wu, J.; Liu, Y.; Zhang, J.; Hao, Y. Nanocrystal-Embedded-Insulator (NEI) Ferroelectric FETs for Negative Capacitance Device and Non-Volatile Memory Applications. Nanoscale Res. Lett. 2019, 14, 115-123. [CrossRef]

100. Kaczmarek, K.T.; Ledingham, P.M.; Brecht, B.; Thomas, S.E.; Thekkadath, G.S.; Lazo-Arjona, O.; Munns, J.H.D.; Poem, E.; Feizpour, A.; Saunders, D.J.; et al. High-speed noise-free optical quantum memory. Phys. Rev. A 2018, 97, 042316. [CrossRef]

101. Chua, L. Resistance switching memories are memristors. Appl. Phys. A 2011, 102, 765-783. [CrossRef]

102. Muthuswamy, B.; Kokate, P. Memristor-Based Chaotic Circuits. IETE Tech. Rev. 2009, 26. [CrossRef]

103. Strukov, D.B.; Snider, G.S.; Stewart, D.R.; Williams, R.S. The missing memristor found. Nature 2008, 453, 80-84. [CrossRef]

104. Adhikari, S.P.; Sah, M.P.; Kim, H.; Chua, L.O. Three Fingerprints of Memristor. IEEE Trans. Circuits Syst. I Regul. Pap. 2013, 60, 3008-3021. [CrossRef]

105. Escudero, M.; Vourkas, I.; Rubio, A.; Moll, F. Memristive Logic in Crossbar Memory Arrays: Variability-Aware Design for Higher Reliability. IEEE Trans. Nanotechnol. 2019, 18, 635-646. [CrossRef]

106. Duan, S.K.; Hu, X.; Wang, L.D.; Li, C.D.; Mazumder, P. Memristor-based RRAM with applications. Sci. China Inf. Sci. 2012, 55, 1446-1460. [CrossRef]

107. Park, W.Y.; Ju, W.; Ko, Y.S.; Kim, S.G.; Ha, T.J.; Lee, J.Y.; Park, Y.T.; Kim, K.W.; Lee, J.C.; Lee, J.H.; et al. Improvement of sensing margin and reset switching fail of RRAM. Solid-State Electron. 2019, 156, 87-91. [CrossRef]

108. Subhechha, S.; Degraeve, R.; Roussel, P.; Goux, L.; Clima, S.; De Meyer, K.; Van Houdt, J.; Kar, G.S. Regular and Inverted Operating Regimes in TiN/a-Si/TiO $\mathrm{x} / \mathrm{TiN}$ RRAM Devices. IEEE Electron. Device Lett. 2018, 39, 351-354. [CrossRef]

109. Lee, C.; Lee, J.; Kim, M.; Woo, J.; Koo, S.M.; Oh, J.M.; Lee, D. Two-Terminal Structured Synaptic Device Using Ionic Electrochemical Reaction Mechanism for Neuromorphic System. IEEE Electron. Device Lett. 2019, 40, 546-549. [CrossRef]

110. Kang, X.; Guo, J.; Gao, Y.; Ren, S.; Chen, W.; Zhao, X. NiO-based resistive memory devices with highly improved uniformity boosted by ionic liquid pre-treatment. Appl. Surf. Sci. 2019, 480, 57-62. [CrossRef]

111. Wang, G.; Hu, L.; Xia, Y.; Li, Q.; Xu, Q. Resistive switching in $\mathrm{FeNi} / \mathrm{Al}_{2} \mathrm{O}_{3} / \mathrm{NiO} / \mathrm{Pt}$ structure with various $\mathrm{Al}_{2} \mathrm{O}_{3}$ layer thicknesses. J. Magn. Magn. Mater. 2020, 493, 165728-165734. [CrossRef]

112. Pal, S.; Bose, S.; Ki, W.-H.; Islam, A. Design of Power- and Variability-Aware Nonvolatile RRAM Cell Using Memristor as a Memory Element. IEEE J. Electron. Devices Soc. 2019, 7, 701-709. [CrossRef]

113. Su, J.; Liu, K.; Wang, F.; Jin, B.; Guo, Y.; Liu, G.; Li, H.; Zhai, T. Van der Waals 2D Transition Metal Tellurides. Adv. Mater. Interfaces 2019, 6, 1900741. [CrossRef]

114. Lv, Z.; Zhou, Y.; Han, S.-T.; Roy, V.A.L. From biomaterial-based data storage to bio-inspired artificial synapse. Mater. Today 2018, 21, 537-552. [CrossRef] 
115. Zheng, L.; Sun, B.; Chen, Y.; Li, T.; Mao, S.; Zhu, S.; Wang, H.; Zhang, Y.; Lei, M.; Zhao, Y. The redox of hydroxyl-assisted metallic filament induced resistive switching memory based on a biomaterial-constructed sustainable and environment-friendly device. Mater. Today Chem. 2018, 10, 167-174. [CrossRef]

116. Bai, Y.; Wu, H.; Wang, K.; Wu, R.; Song, L.; Li, T.; Wang, J.; Yu, Z.; Qian, H. Stacked 3D RRAM Array with Graphene/CNT as Edge Electrodes. Sci. Rep. 2015, 5, 13785. [CrossRef]

117. Delgado-Notario, J.A.; Clericò, V.; Diez, E.; Velázquez-Pérez, J.E.; Taniguchi, T.; Watanabe, K.; Otsuji, T.; Meziani, Y.M. Asymmetric Dual Grating Gate Graphene-based THz detectors. In Proceedings of the 2019 44th International Conference on Infrared, Millimeter, and Terahertz Waves (IRMMW-THz), Paris, France, 1-6 September 2019; pp. 1-2.

118. Kwong Hong Tsang, D.; Lieberthal, T.J.; Watts, C.; Dunlop, I.E.; Ramadan, S.; Del Rio Hernandez, A.E.; Klein, N. Chemically Functionalised Graphene FET Biosensor for the Label-free Sensing of Exosomes. Sci. Rep. 2019, 9, 13946. [CrossRef]

119. Standley, B.; Bao, W.; Zhang, H.; Bruck, J.; Lau, C.N.; Bockrath, M. Graphene-Based Atomic-Scale Switches. Nano Lett. 2008, 8, 3345-3349. [CrossRef]

120. Sarkar, K.J.; Pal, B.; Banerji, P. Graphene Oxide as a Dielectric and Charge Trap Element in Pentacene-Based Organic Thin-Film Transistors for Nonvolatile Memory. ACS Omega 2019, 4, 4312-4319. [CrossRef] [PubMed]

121. Seul Ki, H.; Ji Eun, K.; Sang Ouk, K.; Sung-Yool, C.; Byung Jin, C. Flexible Resistive Switching Memory Device Based on Graphene Oxide. IEEE Electron. Device Lett. 2010, 31, 1005-1007. [CrossRef]

122. Ray, S.C.; Bhunia, S.K.; Saha, A.; Jana, N.R. Graphene oxide (GO)/reduced-GO and their composite with conducting polymer nanostructure thin films for non-volatile memory device. Microelectron. Eng. 2015, 146, 48-52. [CrossRef]

123. Yu, Y.; Zeng, F.; Chen, J.; Kang, J.; Yang, F.; Cao, Y.; Xiang, M. Regulating polycrystalline behavior of the $\beta$-nucleated isotactic polypropylene/graphene oxide composites by melt memory effect. Polym. Compos. 2019, 40, E440-E448. [CrossRef]

124. Jeong, H.Y.; Kim, J.Y.; Kim, J.W.; Hwang, J.O.; Kim, J.E.; Lee, J.Y.; Yoon, T.H.; Cho, B.J.; Kim, S.O.; Ruoff, R.S.; et al. Graphene oxide thin films for flexible nonvolatile memory applications. Nano Lett. 2010, 10, 4381-4386. [CrossRef]

125. Alaabdlqader, H.S.; Sleiman, A.; Sayers, P.; Mabrook, M.F. Graphene oxide-based non-volatile organic field effect memory transistors. IET Circuits Devices Syst. 2015, 9, 67-71. [CrossRef]

126. Khurana, G.; Misra, P.; Katiyar, R.S. Forming free resistive switching in graphene oxide thin film for thermally stable nonvolatile memory applications. J. Appl. Phys. 2013, 114, 124508. [CrossRef]

127. Shin, Y.; Taufique, M.F.N.; Devanathan, R.; Cutsforth, E.C.; Lee, J.; Liu, W.; Fifield, L.S.; Gotthold, D.W. Highly Selective Supported Graphene Oxide Membranes for Water-Ethanol Separation. Sci. Rep. 2019, 9 , 2251. [CrossRef] [PubMed]

128. Su, Y.; Wei, H.; Gao, R.; Yang, Z.; Zhang, J.; Zhong, Z.; Zhang, Y. Exceptional negative thermal expansion and viscoelastic properties of graphene oxide paper. Carbon 2012, 50, 2804-2809. [CrossRef]

129. Zhuang, X.D.; Chen, Y.; Liu, G.; Li, P.P.; Zhu, C.X.; Kang, E.T.; Noeh, K.G.; Zhang, B.; Zhu, J.H.; Li, Y.X. Conjugated-polymer-functionalized graphene oxide: Synthesis and nonvolatile rewritable memory effect. Adv. Mater. 2010, 22, 1731-1735. [CrossRef] [PubMed]

130. Cui, P.; Seo, S.; Lee, J.; Wang, L.; Lee, E.; Min, M.; Lee, H. Nonvolatile Memory Device Using Gold Nanoparticles Covalently Bound to Reduced Graphene Oxide. ACS Nano 2011, 5, 6826-6833. [CrossRef]

131. Li, D.; Zhang, B.; Zhu, C.; Tian, X.; Zhao, Z.; Chen, Y. In-situ growing D-A polymer from the surface of reduced graphene oxide: Synthesis and nonvolatile ternary memory effect. Carbon 2019, 143, 851-858. [CrossRef]

132. Zhuge, F.; Hu, B.; He, C.; Zhou, X.; Liu, Z.; Li, R.-W. Mechanism of nonvolatile resistive switching in graphene oxide thin films. Carbon 2011, 49, 3796-3802. [CrossRef]

133. Ki Hong, S.; Eun Kim, J.; Kim, S.O.; Jin Cho, B. Analysis on switching mechanism of graphene oxide resistive memory device. J. Appl. Phys. 2011, 110, 044506. [CrossRef]

134. Romero, F.J.; Toral-Lopez, A.; Ohata, A.; Morales, D.P.; Ruiz, F.G.; Godoy, A.; Rodriguez, N. Laser-Fabricated Reduced Graphene Oxide Memristors. Nanomaterials (Basel) 2019, 9, 897. [CrossRef]

135. Aziz, T.N.T.A.; Rosli, A.B.; Yusoff, M.M.; Herman, S.H.; Zulkifli, Z. Transparent hybrid ZnO-graphene film for high stability switching behavior of memristor device. Mater. Sci. Semicond. Process. 2019, 89, 68-76. [CrossRef] 
136. Chen, X.; Zhu, X.; Zhang, S.R.; Pan, J.; Huang, P.; Zhang, C.; Ding, G.; Zhou, Y.; Zhou, K.; Roy, V.A.L.; et al. Controlled Nonvolatile Transition in Polyoxometalates-Graphene Oxide Hybrid Memristive Devices. Adv. Mater. Technol. 2019, 4, 1800551. [CrossRef]

137. Gupta, V.; Kapur, S.; Saurabh, S.; Grover, A. Resistive Random Access Memory: A Review of Device Challenges. IETE Tech. Rev. 2019. [CrossRef]

138. Russo, P.; Xiao, M.; Zhou, N.Y. Electrochemical Oxidation Induced Multi-Level Memory in Carbon-Based Resistive Switching Devices. Sci. Rep. 2019, 9, 1564-1573. [CrossRef] [PubMed]

139. Romero, F.J.; Toral, A.; Medina-Rull, A.; Moraila-Martinez, C.L.; Morales, D.P.; Ohata, A.; Godoy, A.; Ruiz, F.G.; Rodriguez, N. Resistive Switching in Graphene Oxide. Front. Mater. 2020, 7, 1-5. [CrossRef]

140. Huang, C.; Peng, J.; Cheng, Y.; Zhao, Q.; Du, Y.; Dou, S.; Tomsia, A.P.; Wagner, H.D.; Jiang, L.; Cheng, Q. Ultratough nacre-inspired epoxy-graphene composites with shape memory properties. J. Mater. Chem. A 2019, 7, 2787-2794. [CrossRef]

141. Akinwande, D.; Huyghebaert, C.; Wang, C.H.; Serna, M.I.; Goossens, S.; Li, L.J.; Wong, H.P.; Koppens, F.H.L. Graphene and two-dimensional materials for silicon technology. Nature 2019, 573, 507-518. [CrossRef]

142. Yin, S.; Gluschke, J.G.; Micolich, A.P.; Nathawat, J.; Barut, B.; Dixit, R.; Arabchigavkani, N.; He, K.; Randle, M.; Kwan, C.P.; et al. Nonvolatile Memory Action Due to Hot-Carrier Charge Injection in Graphene-on-Parylene Transistors. ACS Appl. Electron. Mater. 2019, 1, 2260-2267. [CrossRef]

143. Kim, S.K.; Kim, J.Y.; Choi, S.-Y.; Lee, J.Y.; Jeong, H.Y. Direct Observation of Conducting Nanofilaments in Graphene-Oxide-Resistive Switching Memory. Adv. Funct. Mater. 2015, 25, 6710-6715. [CrossRef]

144. Panin, G.N.; Kapitanova, O.O.; Lee, S.W.; Baranov, A.N.; Kang, T.W. Resistive Switching in Al/Graphene Oxide/Al Structure. Jpn. J. Appl. Phys. 2011, 50, 0701101-0701106.

145. Wang, L.H.; Yang, W.; Sun, Q.Q.; Zhou, P.; Lu, H.L.; Ding, S.J.; Wei Zhang, D. The mechanism of the asymmetric SET and RESET speed of graphene oxide based flexible resistive switching memories. Appl. Phys. Lett. 2012, 100, 063509. [CrossRef]

146. Pradhan, S.K.; Xiao, B.; Mishra, S.; Killam, A.; Pradhan, A.K. Resistive switching behavior of reduced graphene oxide memory cells for low power nonvolatile device application. Sci. Rep. 2016, 6, 26763. [CrossRef] [PubMed]

147. Khurana, G.; Kumar, N.; Chhowalla, M.; Scott, J.F.; Katiyar, R.S. Non-Polar and Complementary Resistive Switching Characteristics in Graphene Oxide devices with Gold Nanoparticles: Diverse Approach for Device Fabrication. Sci. Rep. 2019, 9, 15103. [CrossRef] [PubMed]

148. Wah, L.E. Modeling of Graphene Oxide Memory based on Hybridization State Modulation. Imp. J. Interdiscip. Res. 2017, 3, 152-158.

149. Porro, S.; Accornero, E.; Pirri, C.F.; Ricciardi, C. Memristive devices based on graphene oxide. Carbon 2015, 85, 383-396. [CrossRef]

150. Kumar, R.; Jayaramulu, K.; Maji, T.K.; Rao, C.N. Hybrid nanocomposites of ZIF-8 with graphene oxide exhibiting tunable morphology, significant $\mathrm{CO}_{2}$ uptake and other novel properties. Chem. Commun. (Camb.) 2013, 49, 4947-4949. [CrossRef]

151. Lim, E.W.; Ahmadi, M.T.; Ismail, R. Modeling and simulation of graphene-oxide-based RRAM. J. Comput. Electron. 2016, 15, 602-610. [CrossRef]

152. Chen, H.Y.; Tian, H.; Gao, B.; Yu, S.; Liang, J.; Kang, J.; Zhang, Y.; Ren, T.L.; Wong, H.S.P. Electrode oxide interface engineering by inserting single-layer graphene Application for $\mathrm{HfO}_{\mathrm{X}}$-based resistive random access memory. IEEE Electron. Device Lett. 2012, 10, 2051-2054.

153. Sohn, J.; Lee, S.; Jiang, Z.; Chen, H.Y.; Wong, H.S.P. Atomically thin graphene plane electrode for 3D RRAM. IEEE Electron. Device Lett. 2014, 3, 531-534.

154. Khatami, Y.; Li, H.; Xu, C.; Banerjee, K. Metal-to-Multilayer-Graphene Contact-Part I: Contact Resistance Modeling. IEEE Trans. Electron. Devices 2012, 59, 2444-2452. [CrossRef]

155. Tian, H.; Chen, H.Y.; Gao, B.; Yu, S.; Liang, J.; Yang, Y.; Xie, D.; Kang, J.; Ren, T.L.; Zhang, Y.; et al. Monitoring oxygen movement by Raman spectroscopy of resistive random access memory with a graphene-inserted electrode. Nano Lett. 2013, 13, 651-657. [CrossRef]

156. Hui, F.; Grustan-Gutierrez, E.; Long, S.; Liu, Q.; Ott, A.K.; Ferrari, A.C.; Lanza, M. Graphene and Related Materials for Resistive Random Access Memories. Adv. Electron. Mater. 2017, 3, 1600195. [CrossRef] 
157. Seo, J.T.; Zhu, J.; Sangwan, V.K.; Secor, E.B.; Wallace, S.G.; Hersam, M.C. Fully Inkjet-Printed, Mechanically Flexible $\mathrm{MoS}_{2}$ Nanosheet Photodetectors. ACS Appl. Mater. Interfaces 2019, 11, 5675-5681. [CrossRef] [PubMed]

158. Lee, S.; Lee, Y.; Kim, S.M.; Song, E.B. Fully-transparent graphene charge-trap memory device with large memory window and long-term retention. Carbon 2018, 127, 70-76. [CrossRef]

159. Kafy, A.; Sadasivuni, K.K.; Kim, H.C.; Akther, A.; Kim, J. Designing flexible energy and memory storage materials using cellulose modified graphene oxide nanocomposites. Phys. Chem. Chem. Phys. 2015, 17, 5923-5931. [CrossRef]

160. Qian, K.; Tay, R.Y.; Lin, M.F.; Chen, J.; Li, H.; Lin, J.; Wang, J.; Cai, G.; Nguyen, V.C.; Teo, E.H.; et al. Direct Observation of Indium Conductive Filaments in Transparent, Flexible, and Transferable Resistive Switching Memory. ACS Nano 2017, 11, 1712-1718. [CrossRef]

161. Lee, S.Y.; Duong, D.L.; Vu, Q.A.; Jin, Y.; Kim, P.; Lee, Y.H. Chemically Modulated Band Gap in Bilayer Graphene Memory Transistors with High On Off Ratio. ACS Nano 2015, 9, 9034-9042. [CrossRef] [PubMed]

162. Liu, X.; Li, H.; Zeng, Q.; Zhang, Y.; Kang, H.; Duan, H.; Guo, Y.; Liu, H. Electro-active shape memory composites enhanced by flexible carbon nanotube/graphene aerogels. J. Mater. Chem. A 2015, 3, 11641-11649. [CrossRef]

163. Liu, T.; Wu, W.; Liao, K.N.; Sun, Q.; Gong, X.; Roy, V.A.L.; Yu, Z.Z.; Li, R.K.Y. Fabrication of carboxymethyl cellulose and graphene oxide bio-nanocomposites for flexible nonvolatile resistive switching memory devices. Carbohydr. Polym. 2019, 214, 213-220. [CrossRef]

164. Al-Shawi, A.; Alias, M.; Sayers, P.; Mabrook, M.F. Improved Memory Properties of Graphene Oxide-Based Organic Memory Transistors. Micromachines (Basel) 2019, 10, 643. [CrossRef]

165. Ban, C.; Wang, X.; Zhou, Z.; Mao, H.; Cheng, S.; Zhang, Z.; Liu, Z.; Li, H.; Liu, J.; Huang, W. A Universal Strategy for Stretchable Polymer Nonvolatile Memory via Tailoring Nanostructured Surfaces. Sci. Rep. 2019, 9, 10337-10343. [CrossRef]

166. Cao, Y.; Fu, Y.; Li, D.; Zhu, C.; Zhang, B.; Chen, Y. Organophosphorus-based polymer covalently functionalized reduced graphene oxide: In-situ synthesis and nonvolatile memory effect. Carbon 2019, 141, 758-767. [CrossRef]

167. Church, R.B.; Hu, K.; Magnacca, G.; Cerruti, M. Cations Block Hydrogen-Bonding-Driven Ethanol Permeation through Disordered Drop-Cast Graphene Oxide Membranes. ACS Appl. Nano Mater. 2019, 2, 5389-5398. [CrossRef]

168. Chu, Z.; Wang, Y.; Jiao, L.; Zhang, X. Laser-scribed reduced graphene oxide as counter electrode for dye-sensitized solar cell. Fuller. Nanotub. Carbon Nanostruct. 2019, 27, 914-919. [CrossRef]

169. Markad, G.B.; Padma, N.; Chadha, R.; Gupta, K.C.; Rajarajan, A.K.; Deb, P.; Kapoor, S. Mutual influence on aggregation and magnetic properties of graphene oxide and copper phthalocyanine through non-covalent, charge transfer interaction. Appl. Surf. Sci. 2019. [CrossRef]

170. Bae, H.; Kim, D.; Seo, M.; Jin, I.K.; Jeon, S.B.; Lee, H.M.; Jung, S.H.; Jang, B.C.; Son, G.; Yu, K.; et al. Bioinspired Polydopamine-Based Resistive-Switching Memory on Cotton Fabric for Wearable Neuromorphic Device Applications. Adv. Mater. Technol. 2019, 4, 1900151. [CrossRef]

171. Amri, A.; Hasan, K.; Taha, H.; Rahman, M.M.; Herman, S.; Awaltanova, E.; Kabir, H.; Yin, C.Y.; Ibrahim, K.; Bahri, S.; et al. Surface structural features and optical analysis of nanostructured $\mathrm{Cu}$-oxide thin film coatings coated via the sol-gel dip coating method. Ceram. Int. 2019, 45, 12888-12894. [CrossRef]

172. Chun, S.; Son, W.; Kim, D.W.; Lee, J.; Min, H.; Jung, H.; Kwon, D.; Kim, A.H.; Kim, Y.J.; Lim, S.K.; et al. Water-Resistant and Skin-Adhesive Wearable Electronics Using Graphene Fabric Sensor with Octopus-Inspired Microsuckers. ACS Appl. Mater. Interfaces 2019, 11, 16951-16957. [CrossRef]

173. Salaoru, I.; Maswoud, S.; Paul, S. Inkjet Printing of Functional Electronic Memory Cells: A Step Forward to Green Electronics. Micromachines (Basel) 2019, 10, 417. [CrossRef]

174. Mavuri, A.; Mayes, A.G.; Alexander, M.S. Inkjet Printing of Polyacrylic Acid-Coated Silver Nanoparticle Ink onto Paper with Sub-100 Micron Pixel Size. Materials (Basel) 2019, 12, 2277. [CrossRef]

175. Lyu, D.; Hu, C.; Jiang, Y.; Bai, N.; Wang, Q.; He, D.; Qi, J.; Li, Y. Resistive switching behavior and mechanism of room-temperature-fabricated flexible $\mathrm{Al} / \mathrm{TiS}_{2}-\mathrm{PVP} / \mathrm{ITO} / \mathrm{PET}$ memory devices. Curr. Appl. Phys. 2019, 19, 458-463. [CrossRef] 
176. Jaafar, M.M.; Ooi, P.C.; Razip Wee, M.F.M.; Mohammad Haniff, M.A.S.; Mohamed, M.A.; Chang, E.Y.; Yeop Majlis, B.; Dee, C.F. Electrical bistabilities behaviour of all-solution-processed non-volatile memories based on graphene quantum dots embedded in graphene oxide layers. J. Mater. Sci. Mater. Electron. 2019, 30, 16415-16420. [CrossRef]

177. Gogoi, K.K.; Chowdhury, A. Highly stable write-once-read-many times switching behavior of graphene oxide-polymer nanocomposites. In Proceedings of the International Conference on Advances in Basic Science (ICABS-2019), Bahal, India, 7-9 February 2019; p. 150028.

178. Hassanpour, A.; Nahar, S.; Tong, X.; Zhang, G.; Gauthier, M.A.; Sun, S. Photocatalytic interlayer spacing adjustment of a graphene oxide/zinc oxide hybrid membrane for efficient water filtration. Desalination 2020, 475, 114174. [CrossRef]

179. Li, X.; Fang, X.; Zhang, P.; Yan, J.; Chen, Y.; Chen, X. Preparation and properties of reduced graphene oxide/polyimide composite films. High Perform. Polym. 2019. [CrossRef]

180. Tian, Y.; Song, Y.; Yao, H.; Yu, H.; Tan, H.; Song, N.; Shi, K.; Zhang, B.; Zhu, S.; Guan, S. Improving resistive switching characteristics of polyimide-based volatile memory devices by introducing triphenylamine branched structures. Dyes Pigments 2019, 163, 190-196. [CrossRef]

181. Du, W.; Jin, Y.; Lai, S.; Shi, L.; Shen, Y.; Yang, H. Multifunctional light-responsive graphene-based polyurethane composites with shape memory, self-healing, and flame retardancy properties. Compos. A Appl. Sci. Manuf. 2020, 128, 105686. [CrossRef]

182. Li, S.T.; Jin, X.Z.; Shao, Y.W.; Qi, X.D.; Yang, J.H.; Wang, Y. Gold nanoparticle/reduced graphene oxide hybrids for fast light-actuated shape memory polymers with enhanced photothermal conversion and mechanical stiffness. Eur. Polym. J. 2019, 116, 302-310. [CrossRef]

183. Zhang, K.; Zhang, H.; Liu, P.; Zhang, C.; Li, W.; Chen, X.; Ma, F. Electrophoretic deposition of graphene oxide on NiTi alloy for corrosion prevention. Vacuum 2019, 161, 276-282. [CrossRef]

184. Lin, C.C.; Chen, Y.D.; Lin, N.C. Graphene Oxide Based Device for Flexible RRAM Application. IEEE Electron. Device Lett. 2013, 9, 396-398.

185. Midya, A.; Gogurla, N.; Ray, S.K. Flexible and transparent resistive switching devices using Au nanoparticles decorated reduced graphene oxide in polyvinyl alcohol matrix. Curr. Appl. Phys. 2015, 15, 706-710. [CrossRef]

186. Liu, J.; Yin, Z.; Cao, X.; Zhao, F.; Wang, L.; Huang, W.; Zhang, H. Fabrication of flexible, all-reduced graphene oxide non-volatile memory devices. Adv. Mater. 2013, 25, 233-238. [CrossRef]

187. Yuan, F.; Ye, Y.R.; Wang, J.C.; Zhang, Z.; Pan, L.; Xu, J.; Lai, C.S. Retention behavior of graphene oxide resistive switching memory on flexible substrate. IEEE Electron. Device Lett. 2013, 5, 288-290.

188. Wu, L.; Guo, J.; Zhong, W.; Zhang, W.; Kang, X.; Chen, W.; Du, Y. Flexible, multilevel, and low-operating-voltage resistive memory based on $\mathrm{MoS}_{2}-\mathrm{rGO}$ hybrid. Appl. Surf. Sci. 2019, 463, 947-952. [CrossRef]

189. Wu, X.; Ge, R.; Chen, P.A.; Chou, H.; Zhang, Z.; Zhang, Y.; Banerjee, S.; Chiang, M.H.; Lee, J.C.; Akinwande, D. Thinnest Nonvolatile Memory Based on Monolayer h-BN. Adv. Mater. 2019, 31, e1806790. [CrossRef]

190. Li, L. Ternary Memristic Effect of Trilayer-Structured Graphene-Based Memory Devices. Nanomaterials (Basel) 2019, 9, 518. [CrossRef]

191. Lynch, I. Far-reaching effects from carbon nanotubes. Nat. Nanotechnol. 2019, 14, 639-640. [CrossRef]

(C) 2020 by the authors. Licensee MDPI, Basel, Switzerland. This article is an open access article distributed under the terms and conditions of the Creative Commons Attribution (CC BY) license (http://creativecommons.org/licenses/by/4.0/). 